\title{
AN INTEGRATED FUZZY MCGDM APPROACH FOR SUPPLIER SELECTION PROBLEM
}

\author{
Gul POLAT, Ekin ERAY, Befrin Neval BINGOL \\ Department of Civil Engineering, Faculty of Civil Engineering, Istanbul Technical University, \\ Maslak, 34469 Istanbul, Turkey
}

Received 23 Jan 2017; accepted 25 May 2017

\begin{abstract}
Materials constitute a large proportion of the total project cost and the absence of right materials in the right quantities and quality on site when needed is one of the most commonly experienced causes of delays in construction projects. Although supplier selection is a strategic issue, contractors generally select suppliers based on their past experiences, which may result in selecting wrong suppliers. Supplier selection decision is generally made by multiple decision makers and is affected by several criteria. Therefore, selecting the right supplier among many alternatives considering several compromising and conflicting criteria is a multi-criteria group decision-making (MCGDM) problem. This paper proposes an integrated fuzzy MCGDM approach, which employs fuzzy analytic hierarchy process (AHP) and fuzzy Technique for Order Preference by Similarity to Ideal Solution (TOPSIS) together, for the supplier selection problem. In the proposed approach, fuzzy AHP is used to analyse the structure of the supplier selection problem and to determine the weights of the criteria, and the fuzzy TOPSIS method is employed to rank the alternative suppliers. The proposed approach is applied to a problem of selecting the most appropriate rail supplier and company management found the proposed decision approach satisfactory and implementable in future supplier selection problems.
\end{abstract}

Keywords: supplier selection, MCGDM, fuzzy AHP, fuzzy TOPSIS, integrated approach, case study.

\section{Introduction}

A construction project highly depends on having the right people with right skills and the right materials and equipment in the right place at the right time that are required to complete the project on time and on budget. The cost of materials and equipment amounts to almost $50-60 \%$ of the overall project cost (Akintoye 1995; Wong, Norman 1997; Ibn-Homaid 2002; Kim, S., Kim, Y. 2014), and this amount can go up to $70 \%$ depending on the type of project and the extent of mechanization and plant used (Donyavi, Flanagan 2009). Moreover, the absence of right materials in the right quantities and quality on site when needed is one of the most commonly experienced causes of delays in construction projects (Polat, Arditi 2005). Indeed, construction materials management affects $80 \%$ of the project schedule (Safa et al. 2014) and losses in labour productivity resulting from non-availability of materials have been estimated to be 6-8\% (Muya et al. 1997).

It is commonly acknowledged that an effective and optimized management of the construction material flow may play a significant role in enhancing the effectiveness of a contractor and achieving project objectives in terms of time, cost and quality by means of ensuring the availability of sufficient quantities of materials and equipment for construction needs and minimizing the surpluses at the end of the project (Thomas et al. 2005; Donyavi, Flanagan 2009). Construction materials management is defined as "the planning and controlling of all activities necessary for ensuring and confirming that the correct and accurate quantity and quality of materials and equipment are appropriately specified in a timely manner, are obtained at a reasonable cost, and are available when needed" (Safa et al. 2014).

The main problems resulting from poor construction materials management can be summarized as follows: failure to order on time, delivery at the wrong time, errors in quantity take-offs, receiving wrong materials, lost or damaged materials, theft of materials from delivery into production, and double handling (Donyavi, Flanagan 2009). Most of these problems can be overcome by a proper purchasing process. The purchasing function of a construction company is central to materials management and mainly involves the commitment of project funds for construction materials (Samarasinghe et al. 2012).

Purchasing is defined as "a fundamental function of material procurement that refers to the acquisition

Corresponding author: Gul Polat

E-mail:polatgu@itu.edu.tr 
of goods and services and an establishment of mutually acceptable terms and conditions between a seller and a buyer" (Hadikusumo et al. 2005). Purchasing within an organization mainly involves all of the activities associated with the buying process, which include: determining the need, selecting and awarding suppliers, analysing proposals, arriving at a proper price, specifying terms and conditions, issuing the contract or order, ensuring proper delivery, inspecting goods supplied, and maintaining a variety of purchasing records (Van Weele 2005; Safa et al. 2014).

One of the most important tasks of the purchasing function is the selection of the right suppliers, and thereby the acquisition of required materials (Aretoulis et al. 2010; Monczka et al. 2011; Zeydan et al. 2011). In today's competitive business environment, it is impossible to produce high quality products with low cost without satisfactory suppliers. Therefore, selection and maintenance of a competent group of suppliers is one of the most important purchasing decisions (Weber et al. 1991).

Supplier evaluation/selection is the process of finding the appropriate suppliers, who are capable of providing the buyer with the right quality products and/or services at the right price, in the right quantities and at the right time (Zhang et al. 2009). The objective of supplier selection process is to identify suppliers with the highest potential for meeting a company's needs consistently and at an acceptable overall performance (Li et al. 2008).

Supplier selection has great impact on the coordination of various company services, such as production, transportation, storage, or purchases, as well as its competitive position in the market (Önüt et al. 2009). Therefore, the decision concerning supplier selection must comply with the company's long-term strategies and competitive positioning (Plebankiewicz, Kubek 2016). According to Aretoulis et al. (2010), supplier selection plays a critical role in the success or failure of construction projects. Ho and Nguyen (2007) state that maintaining a strong relationship with suppliers is crucial for creating competitive advantage in today's construction environment. Selecting the right suppliers significantly reduces purchasing and operational costs, improves competitiveness in the market, improves the quality of end products, and enhances end user satisfaction (Önüt et al. 2009; Zeydan et al. 2011).

Material-intensive nature of the construction industry makes supplier selection critical and there are several studies that focus on either identification of the most commonly used criteria for supplier selection in the construction industry or development of various supplier evaluation/selection methodologies, tools, and methods. However, some of these developed methodologies, tools, and methods are not widely accepted, applied and operated by construction professionals as they are based on complex computational and mathematical models and unnecessarily difficult to understand and use. Moreover, the practitioners may not believe that the available methods improve the quality of their decisions (Wang, Tang 2015).
Therefore, construction professionals still tend to select their suppliers based on past experiences rather than objective and systematic approaches (Formoso, Revelo 1999; Donyavi, Flanagan 2009; Chen et al. 2011).

Selecting suppliers based on solely past experiences may cause selecting wrong suppliers, which in turn bring about quality problems, cost overruns, delays, environmental problems, etc. Indeed, Monczka et al. (2011) found that nearly $50 \%$ of the quality problems result from working with wrong suppliers and poor management of the supply chain. Meng (2013) claims that the traditional adversarial supply chain relationship brings about various problems, e.g., claims, conflicts, disputes, low productivity, delays, cost overruns, quality defects, and customer dissatisfaction.

Verma and Pullman (1998) found that even though managers claim that quality is the most important criterion in selecting a supplier, in real life, they predominantly select suppliers based on two criteria, namely product price and delivery performance. Li et al. (2008) report that simply looking for the suppliers, who offer the lowest prices, is not "efficient sourcing" any more. Ho et al. (2010) state that traditional cost-based approach is not supportive and robust, and cannot guarantee that the selected supplier is global optimal as the customer-oriented criteria (e.g., quality, delivery, flexibility, etc.) are not considered. Similarly, Benton and McHenry (2010) state that construction companies should select their material suppliers based on value-added capabilities rather than competitive process considering today's aggressive sourcing environment. Moreover, Wu et al. (2010) and Ho et al. (2010) highlight that the supplier selection decision must not depend solely on product price or quality measures. Therefore, construction companies should take into account not only the price but also several compromising and conflicting criteria, e.g., quality of products and services, delivery flexibility, performance history, warranties, technical capability and financial position, in the supplier selection decision-making process (Benton, McHenry 2010; Samarasinghe et al. 2012; Plebankiewicz, Kubek 2016).

In most cases, the problem of supplier selection deals with more than one supplier and the supplier selection is made by multiple decision makers, who have different points of views (Plebankiewicz, Kubek 2016). Selecting suppliers from several possible alternatives with various levels of capabilities and potential is not an easy task for decision makers. Supplier selection should be considered as a MCGDM problem (Li et al. 2008). Moreover, during the supplier selection process, numerous criteria are simultaneously taken into account. Some of these criteria are quantitative and can be measured directly (e.g., the price of the product). On the other hand, the majority of them is qualitative and can be evaluated subjectively (e.g., the quality of products and services).

In most of the real life problems, the information is uncertain and human's thoughts are imprecise, thus, it is almost impossible for decision makers to provide exact 
numerical values during the comparison and/or evaluation process. In these cases, decision makers may prefer to specify their preferences by linguistic variables, whose values are words or sentences in a natural or artificial language, and give interval judgments rather than fixed value judgments (Zadeh 1975). Fuzzy set theory is a powerful tool for reflecting human reasoning and handling uncertainty and incomplete information when generating decisions (Wong, Lai 2011). Therefore, integrating the fuzzy set theory with multi-criteria-decision-making (MCDM) methods may help to make the assessment process more flexible and suitable for decision makers' imprecise nature of preferences (Kahraman et al. 2010).

The main objective of this study is to propose an integrated fuzzy MCGDM approach, which employs fuzzy AHP and fuzzy TOPSIS together, for the selection of the most appropriate rail supplier among a set of available alternatives considering several compromising and conflicting criteria. In the proposed approach, fuzzy AHP is used to analyze the structure of the supplier selection problem and to determine the weights of the criteria, and the fuzzy TOPSIS method is employed to obtain the ranking of the alternative suppliers. In order to illustrate how the proposed approach can be used in a real situation, it was applied to a problem of selecting the most appropriate supplier to be worked with in an international railway construction project.

\section{Supplier selection process and previous studies in supplier selection}

The basic steps of the supplier selection process are presented in Figure 1 (Samarasinghe et al. 2012; Plebankiewicz, Kubek 2016).

As seen in Figure 1, supplier selection process requires making a number of important decisions and identification of the supplier selection criteria and selection of suppliers are two of the most important decisions that have to be made during the supplier selection process.

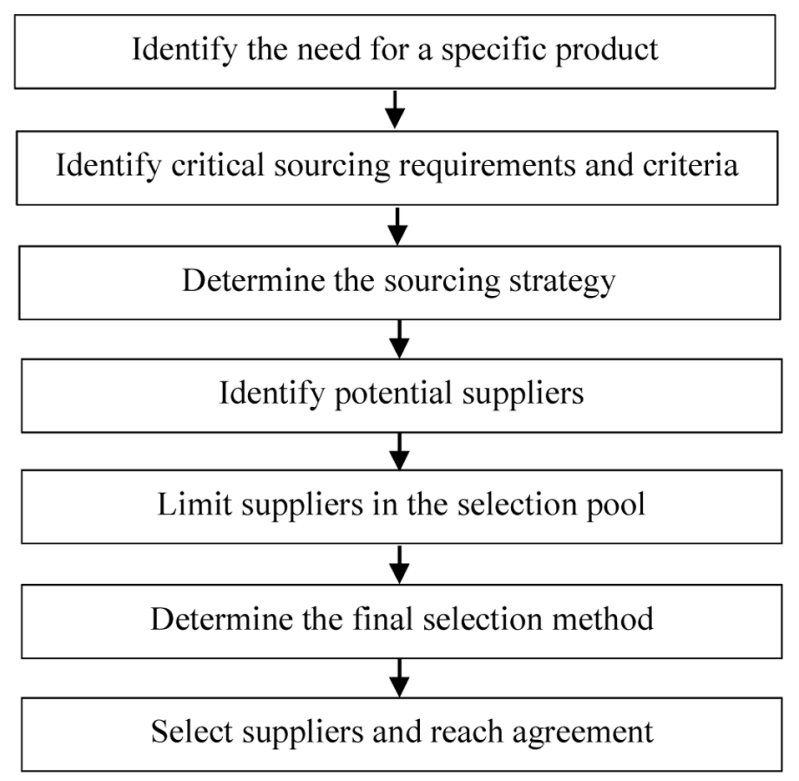

Fig. 1. The basic steps of the supplier selection process

In the construction management literature, several studies have dealt with the problem of evaluating/selecting suppliers. These studies have different focuses. While some of them aimed to identify the most commonly used criteria for supplier selection in the construction industry, the remainders proposed various supplier evaluation/selection methodologies, tools, and methods.

Formulizing the problem of supplier evaluation/selection is very complicated because of the fact that it is affected by the combination of several quantitative (e.g., the price of the product) and qualitative (e.g., the quality of products and services) criteria, most of which are contradictory (e.g., the quality of products and services vs. the price of the product), and there is no consensus about the criteria that should be taken into account during the supplier evaluation process in the construction industry. In the construction management literature, various

Table 1 . The most frequently cited supplier selection criteria in the construction industry

\begin{tabular}{ll}
\hline \multicolumn{1}{c}{ Supplier Selection Criteria } & \multicolumn{1}{c}{ Sources } \\
\hline Total cost of the product & $\begin{array}{l}\text { Kannan and Tan (2002), Ho and Nguyen (2007), Aretoulis } \text { et al. (2010), Benton and } \\
\text { McHenry (2010), Schramm and Morais (2012), Safa } \text { et al. (2014), Plebankiewicz and } \\
\text { Kubek (2016) }\end{array}$ \\
\hline Payment conditions & Aretoulis et al. (2010), Schramm and Morais (2012), Plebankiewicz and Kubek (2016) \\
\hline Lead time & Schramm and Morais (2012), Safa et al. (2014), Plebankiewicz and Kubek (2016) \\
\hline Delivery performance/flexibility & $\begin{array}{l}\text { Kannan and Tan (2002), Ho and Nguyen (2007), Aretoulis } \text { et al. (2010), Benton and } \\
\text { McHenry (2010), Schramm and Morais (2012), Plebankiewicz and Kubek (2016) }\end{array}$ \\
\hline Quality of the products and services & $\begin{array}{l}\text { Kannan and Tan (2002), Ho and Nguyen (2007), Aretoulis } \text { et al. (2010), Benton and } \\
\text { McHenry (2010), Schramm and Morais (2012), Plebankiewicz and Kubek (2016) }\end{array}$ \\
\hline Guarantee period & Plebankiewicz and Kubek (2016) \\
\hline Technical expertise of the supplier & Ho and Nguyen (2007), Plebankiewicz and Kubek (2016) \\
\hline Reputation of the supplier & Kannan and Tan (2002), Plebankiewicz and Kubek (2016) \\
\hline Performance history of the supplier & Schramm and Morais (2012), Safa et al. (2014), Plebankiewicz and Kubek (2016) \\
\hline Communication with the supplier & Ho and Nguyen (2007), Schramm and Morais (2012) \\
\hline
\end{tabular}


supplier selection criteria have been proposed by several researchers. The most frequently cited supplier selection criteria are presented in Table 1.

Several evaluation/selection methodologies, tools, and methods have been developed for supplier selection in the manufacturing industry. Some of them can be summarized as follows. Ghodsypour and O'Brien (1998) proposed an integrated approach, which combines AHP and Linear Programming methods, to solve supplier selection problem. Liu et al. (2000) used Data Envelopment Analysis (DEA) to compare suppliers for supplier selection and performance improvement. Tam and Tummala (2001) applied AHP in supplier selection of telecommunication systems. Choy et al. (2003) designed a case based intelligent supplier relation management system. Kahraman et al. (2003) proposed fuzzy AHP method to solve a supplier selection problem in white goods producing industry. Wang (2005) applied fuzzy decision optimum model in selecting supplier. Önüt et al. (2009) developed a supplier evaluation model based on the fuzzy Analytic Network Process (ANP) and fuzzy TOPSIS methods to select the most appropriate supplier in a telecommunication company. Zhang et al. (2009) introduced an approach for supplier selection based on vague sets group decision. Sevkli (2010) proposed fuzzy Elimination and Choice Expressing the Reality (ELECTRE) method to solve supplier selection problem in a manufacturing company. Wu et al. (2010) proposed fuzzy multi-objective programming for solving supplier selection problem. Mendoza and Ventura (2013) developed a mixed integer nonlinear programming model to properly allocate order quantities to the selected set of suppliers while taking into account the purchasing, inventory, and transportation costs under suppliers' capacity and quality constraints. Junior et al. (2014) compared the performances of fuzzy AHP and fuzzy TOPSIS in solving supplier selection problem and found that Fuzzy TOPSIS method was better suited to the problem of supplier selection in regard to changes of alternatives and criteria, agility and number of criteria and alternative suppliers. Kannan et al. (2015) proposed Fuzzy Axiomatic Design (FAD) approach to select the best green supplier for Singapore-based plastic manufacturing company. Yazdani et al. (2016) proposed an integrated model called weighted aggregated sum product assessment (WASPAS), which uses step-wise weight assessment ratio analysis (SWARA) and quality function deployment (QFD) together, to select green suppliers.

Construction is a different type of production than manufacturing and it can be described as a product development process, starting from product design through process design to facility construction (Ballard, Howell 1997). Ballard and Howell (1998) and Koskela (1992) summarize these differentiating characteristics as one-ofa-kind nature of construction projects, site production, and temporary multi-organization. While there is a single and unique end product produced once in construction, large numbers of similar units are repetitively produced in manufacturing (Halpin, Senior 2011). Every construction project is unique and construction supply chain can be considered as a typical make-to-order supply chain in which every project creates a new product or prototype (Vrijhoef, Koskela 2000). Moreover, products are designed and produced without a designated purchaser in manufacturing, whereas product is designed and constructed after the purchaser (i.e., client) is identified in construction. Variety and quantity of required materials may change according to the type of the project in question. For instance, the types and quantities of materials used for heavy construction considerably vary from those used in building construction. Unfamiliarity with the materials and/or technology required by the project in question makes the supplier selection problem complex in construction. Every construction project is built in different location and every construction site can be considered as a "factory" contrary to "fixed position manufacturing". A wide range of materials in large quantities are delivered to the construction site where the facility is to be built and the product (i.e., facility) is assembled from these incoming materials on site. This rootednessin-place brings about uncertainty and differentiation such as soil conditions, geographic conditions, wind load, seismic conditions, weather conditions, machine breakdowns, losses caused by accidents and other incidents, different codes and regulations, unfamiliarity with the local suppliers and subcontractors and difficulty in shortlisting them, etc. (Ballard, Howell 1998; Chen et al. 2011). In construction projects, several organizations temporarily come together in order to produce one-off product, which makes the construction supply chain instable and fragmented (Vrijhoef, Koskela 2000). The supplier selection problem in the construction industry is slightly different from the one in the manufacturing industry as a result of these differentiating characteristics of the construction industry.

The number of the studies that deal with supplier selection problem in the construction industry is limited when compared to the number of studies in the manufacturing industry. Aretoulis et al. (2010) provided a standardized approach in selecting the best construction material supplier through the formation and use of an appropriate mathematical equation based on multiple criteria. Chen et al. (2011) proposed an ANP model that combines qualitative and quantitative methods to select optimal building engineering materials supplier. Schramm and Morais (2012) proposed a model based on Simple Multi-Attribute Rating Technique Exploiting Ranking (SMARTER) method to solve supplier selection problem in the construction industry. Ren et al. (2012) proposed an innovative approach to the integration of Building Information Modeling (BIM) and electronic commerce (e-commerce) in a material procurement process. Guan et al. (2013) built a selection decision-making evaluation index system for selection of cement suppliers in a national highway project in Republic of Congo based 
on fuzzy AHP and fuzzy matter-element methods. Safa et al. (2014) developed an integrated construction materials management system model for the industrial construction sector and used the TOPSIS method to rank the suppliers. Polat and Eray (2015) proposed the integration of AHP and Evidential Reasoning (ER) methods for solving the supplier selection problem. Plebankiewicz and Kubek (2016) proposed the use of AHP and fuzzy AHP methods to select building material suppliers.

When the supplier selection models developed in the manufacturing and construction industries are compared, it can be observed that the selection models developed in the manufacturing industry use either hybrid and modular methods (e.g., integration of fuzzy ANP and fuzzy TOPSIS, integration of AHP and linear programming, etc.) and/or modifications of previously developed well-known methods with fuzzy and grey number theory (e.g., fuzzy AHP, fuzzy TOPSIS, fuzzy ELECTRE, fuzzy multi-objective programming, FAD, etc.) or relatively recently developed MCDM methods (i.e., WASPAS, SWARA, etc.). On the other hand, the supplier selection models developed in the construction industry mostly use single, well-known, and relatively previously developed MCDM methods (i.e., AHP, ANP, SMARTER, etc.).

As mentioned in the previous section, supplier selection can be considered as a MCGDM problem in which the imprecise and uncertain evaluations of multiple decision makers on numerous alternatives with respect to various compromising and conflicting quantitative and/ or qualitative criteria should be considered simultaneously. Supplier selection problem mainly consists of two parts. The first part includes structuring the hierarchy of the problem, identifying the selection criteria, and determining of the relative importance weights of these criteria. The relative importance weights of the identified criteria can be directly provided by the decision makers. However, this means is not systematic and it may cause subjective judgements. Therefore, the relative importance weights of the identified criteria should be determined through a systematic method. The second part involves ranking numerous alternatives through the evaluations performed by multiple decision makers with respect to the pre-identified criteria considering their relative importance weights. Since the supplier selection problem comprises two different parts, using a single MCDM may not be adequate. Moreover, supplier selection is generally made by multiple decision makers, whose thoughts are imprecise and uncertain. Thus, there is a need for developing a new supplier selection model, which uses the integration of different MCDM methods modified with the fuzzy set theory (Zavadskas et al. 2014; Mardani et al. 2015 ) and allows aggregating opinions of multiple decision makers.

This study aims to overcome the shortcomings of the previous studies and proposes the integration of two wellknown MCDM methods modified with fuzzy set theory, namely fuzzy AHP and fuzzy TOPSIS, for solving the supplier selection problem in construction. Fuzzy AHP is a systematic approach, which combines the classical AHP method with fuzzy set theory. It was developed to solve the hierarchical structure of selection and justification problems in fuzzy environments. The ultimate goal of fuzzy AHP is to obtain relative importance weights of the determined criteria and alternatives. The relative importance weights are the main output of the fuzzy AHP, and some researchers perceive these relative importance weights as potential inputs for other MCDM methods (Abdullah, Zulkifli 2015; Efe 2016). In this study, the relative importance weights of the supplier selection criteria were determined by the fuzzy AHP method, and these weights were used as inputs for the fuzzy TOPSIS method. Fuzzy TOPSIS, which is the fuzzy extension of the classical TOPSIS, is a well-known MCDM method and is based on choosing the best alternative that has the shortest distance from the positive-ideal alternative and the longest distance from the negative-ideal alternative. Fuzzy extension of TOPSIS enables decision makers to evaluate the performances of the alternatives with respect to several criteria in linguistic terms (Chen 2000). In the proposed approach, the relative weights of the selection criteria are obtained from the fuzzy AHP. The detailed information about these methods is given in the following section.

The integration of fuzzy AHP and fuzzy TOPSIS methods have been successfully implemented in various fields such as performance evaluation (Sun 2010), facility location selection (Kahraman et al. 2010), quantifying risks in a supply chain (Samvedi et al. 2013), handling equipment selection (Yazdani-Chamzini 2014), construction project selection and risk assessment (Taylan et al. 2014), intelligent building assessment (Kaya, Kahraman 2014), ERP system selection (Efe 2016), etc.

\section{Mathematical background}

In this section, the principles of fuzzy set theory, and fuzzy AHP and fuzzy TOPSIS methodologies will be briefly explained.

\subsection{Fuzzy set theory}

In fuzzy set theory, which was first introduced by Zadeh (1965), the elements in fuzzy sets have been defined by their degrees of membership. On the other hand, in classical set theory, the membership of elements in a set is defined in binary terms. In this study, triangular fuzzy number (TFN) is used for fuzzy AHP and fuzzy TOPSIS as it is intuitively easy for decision makers to understand and calculate (Dağdeviren et al. 2009).

TFN ( $\tilde{\mathrm{A}})$ is defined by three crisp numbers expressed as a triple $(l, m, u)$, where $l \leq m \leq u$, and its membership function $\left(\mu_{\tilde{\mathrm{A}}}(x)\right)$ whose values can be any number in the interval $[0,1]$, where 0 means that the value $(x)$ does not belong to the set in question and 1 means that the value $(x)$ completely belongs to the set. The membership 


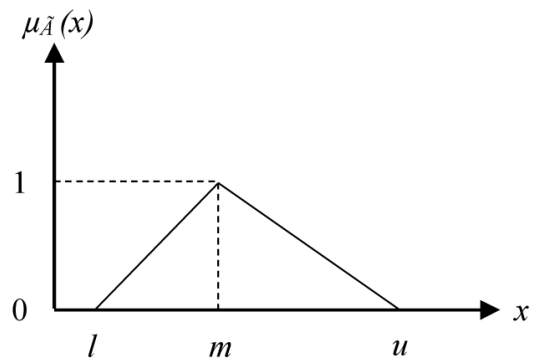

Fig. 2. The membership function of a triangular fuzzy number

function $\left(\mu_{\tilde{A}}(x)\right)$ of a fuzzy number $\tilde{A}(l, m, u)$ can be expressed as in Eqn (1):

$$
\mu \tilde{A}(x)=\left\{\begin{array}{cc}
(x-l) /(m-l), & l \leq x \leq u \\
(u-x) /(u-m), & m \leq x \leq u \\
0, & \text { otherwise }
\end{array}\right.
$$

In Eqn (1), $l$ and $u$ are the lower and upper bounds, and $m$ is the modal value of the fuzzy number $\tilde{A}(l, m, u)$. The membership function of a TFN is shown in Figure 2.

The operational laws of TFNs $\tilde{A}_{1}\left(l_{1}, m_{1}, u_{1}\right)$ and $\tilde{A}_{2}\left(l_{2}, m_{2}, u_{2}\right)$ are displayed in Eqns (2)-(6) (Hsieh et al. 2004).

Addition of a TFN:

$$
\begin{aligned}
\tilde{A}_{1} \oplus \tilde{A}_{2} & =\left(l_{1}, m_{1}, u_{1}\right) \oplus\left(l_{2}, m_{2}, u_{2}\right) \\
& =\left(l_{1}+l_{2}, m_{1}+m_{2}, u_{1}+u_{2}\right) .
\end{aligned}
$$

Subtraction of a TFN:

$$
\begin{aligned}
\tilde{A}_{1} \theta \tilde{A}_{2} & =\left(l_{1}, m_{1}, u_{1}\right)-\left(l_{2}, m_{2}, u_{2}\right) \\
& =\left(l_{1}-u_{2}, m_{1}-m_{2}, u_{1}-l_{2}\right) .
\end{aligned}
$$

Multiplication of a TFN:

$$
\begin{aligned}
\tilde{A}_{1} \otimes \tilde{A}_{2} & =\left(l_{1}, m_{1}, u_{1}\right) \otimes\left(l_{2}, m_{2}, u_{2}\right) \\
& =\left(l_{1} \cdot l_{2}, m_{1} \cdot m_{2}, u_{1} \cdot u_{2}\right),
\end{aligned}
$$

where $l_{i}>0 ; m_{i}>0 ; u_{i}>0$.

Division of a TFN:

$$
\begin{aligned}
\tilde{A}_{1} \varnothing \tilde{A}_{2} & =\left(l_{1}, m_{1}, u_{1}\right) \div\left(l_{2}, m_{2}, u_{2}\right) \\
& =\left(l_{1} / u_{2}, m_{1} / m_{2}, u_{1} / l_{2}\right),
\end{aligned}
$$

where $l_{i}>0 ; m_{i}>0 ; u_{i}>0$.

Reciprocal of a TFN:

$$
\tilde{A}^{-1}=\left(l_{1}, m_{1}, u_{1}\right)^{-1}=\left(1 / u_{1}, 1 / m_{1}, 1 / l_{1}\right),
$$

where $l_{i}>0 ; m_{i}>0 ; u_{i}>0$.

\subsection{The fuzzy AHP method}

AHP, which was first developed by Saaty (1980), is one of the most powerful techniques for solving complex decision problems. The main idea behind AHP is to decompose any complicated and unstructured multicriteria decision problem into manageable and measur- able sub-problems. AHP is a MCDM approach based on an additive weighting process. This method consists of four main steps. First, a complex decision problem is structured as a hierarchy of interrelated decision elements (i.e., goal, main criteria, sub-criteria, alternatives). Second, the decision elements in the corresponding level are compared in pairs based on a standardized nine-point scale of measurement according to their levels of influence on the specified element in the higher level of the decision hierarchy. Third, pairwise comparison matrices are synthesized in order to find the relative importance of each criterion/alternative. Finally, the consistency ratios of the pairwise comparisons are determined in order to see whether the judgment matrices are consistent or not (Saaty 1980). The main superiority of AHP is that it enables decision makers to consider intangible qualitative data and tangible quantitative criteria simultaneously (Dağdeviren et al. 2009).

Although the classical AHP has been widely accepted and extensively used by academics and professionals for solving MCDM problems in various fields, it is not capable of reflecting human's vague nature of opinions and handling uncertainty (Sun 2010). Since the information is uncertain and human's thoughts are imprecise in most of the in real life problems, it is almost impossible for decision makers to provide exact numerical values during the comparison and/or evaluation process. Thus, decision makers may prefer to specify their preferences by linguistic variables, whose values are words or sentences in a natural or artificial language, and give interval judgments rather than fixed value judgments (Zadeh 1975).

Fuzzy set theory is a powerful tool for reflecting human reasoning and handling uncertainty and incomplete information when generating decisions (Wong, Lai 2011). Therefore, integrating the fuzzy set theory with the AHP method may help to make the assessment process more flexible and suitable for decision makers' imprecise nature of preferences (Kahraman et al. 2010). The main idea behind fuzzy AHP is to use linguistic statements, which are represented by TFNs instead of crisp numbers, in the pairwise comparison. Fuzzy AHP has become a very popular MCDM method as it enables decision makers to handle uncertainty, imprecise and incomplete information inherent in decision problems by using the concepts of fuzzy set theory and hierarchical structure analysis.

In the literature, there are different methods proposed for the fuzzification of AHP (e.g., Van Laarhoven, Pedrcyz 1983; Buckley 1985; Chang 1996). In this study, Buckley's (1985) method has been employed. The steps of this method are briefly explained below (Hsieh et al. 2004; Sun 2010; Yazdani-Chamzini 2014):

Step 1: Build the hierarchical structure of the decision problem.

Step 2: Consult decision makers and construct pairwise comparison matrices for all attributes in the decision hierarchy. Each element $\left(\tilde{a}_{i j}\right)$ in the pairwise comparison 
matrix $(\tilde{A})$ is a linguistic term presenting which is the more important of two attributes. The pairwise comparison matrix is given by:

$$
\tilde{A}_{k}=\left[\begin{array}{cccc}
1 & \tilde{a}_{12} & \ldots & \tilde{a}_{1 n} \\
\tilde{a}_{21} & 1 & \ldots & \tilde{a}_{2 n} \\
\vdots & \vdots & \ddots & \vdots \\
\tilde{a}_{n 1} & \tilde{a}_{n 2} & \ldots & \tilde{a}_{n n}
\end{array}\right]=\left[\begin{array}{cccc}
1 & \tilde{a}_{12} & \ldots & \tilde{a}_{1 n} \\
\tilde{a}_{12} & 1 & \ldots & \tilde{a}_{2 n} \\
\vdots & \vdots & \ddots & \vdots \\
\tilde{a}_{1 n}{ }^{-1} & \tilde{a}_{2 n}{ }^{-1} & \ldots & \tilde{a}_{n n}
\end{array}\right],
$$

where $\tilde{A}_{k}$ is the pairwise comparison matrix constructed by the $k^{\text {th }}$ decision maker for any attribute. During the evaluation process, linguistic scales are used.

Step 3: Aggregate the decision makers' pairwise comparison matrices by using the geometric mean. The aggregated TFN of all decision makers' fuzzy judgments in a certain case $\tilde{r}_{i j}=\left(l_{i j}, m_{i j}, u_{i j}\right)$ is calculated using Eqn (7):

$$
\tilde{r}_{i j}=\left[\prod_{k=1}^{K} \tilde{a}_{i j k}\right]^{1 / K},
$$

where $\tilde{a}_{i j k}$ is the fuzzy comparison value of attribute $i$ to attribute $j$ in the form of TFN specified by the $k^{\text {th }}$ decision maker and $K$ is the number of decision makers.

Step 4: Aggregate the fuzzy comparison values of attribute $i$ to all attributes at the same evaluation dimension by using the geometric mean. The aggregated TFN of an attribute $i$ in a certain case $\tilde{r}_{i}=\left(l_{i}, m_{i}, u_{i}\right)$ is calculated using Eqn (8):

$$
\tilde{r}_{i}=\left[\prod_{j=1}^{N} \tilde{r}_{i j}\right]^{1 / N},
$$

where $\tilde{r}_{i j}$ is the aggregated fuzzy comparison value of attribute $i$ to attributes $j$ in the form of TFN and $N$ is the number of attributes at the same evaluation dimension.

Step 5: Calculate the fuzzy weight of each attribute $i\left(\tilde{w}_{i}\right) . \tilde{w}_{i}=\left(l_{w i}, m_{w i}, u_{w i}\right)$ can be found using Eqn (9):

$$
\tilde{w}_{i}=\tilde{r}_{i} \otimes\left(\tilde{r}_{1} \oplus \tilde{r}_{2} \oplus \ldots \oplus \tilde{r}_{N}\right)^{-1},
$$

where $\tilde{r}_{i}$ is the aggregated TFN of attribute $i$ in the form of TFN and $N$ is the number of attributes at the same evaluation dimension.

Step 6: Defuzzify the triangular fuzzy weights. For this purpose, the Best Nonfuzzy Performance (BNP) value is calculated. Different methods, e.g., center of area (COA), graded mean integration (GMI), etc. can be used to calculate BNP for TFNs (Rutkowski 2008). In this study, the COA method is preferred. In this method, $B N P_{w i}$ for attribute $i$ is calculated using Eqn (10):

$$
B N P_{w i}=\left[\left(u_{w i}-l_{w i}\right)+\left(m_{w i}-l_{w i}\right)\right] / 3+l_{w i} .
$$

Step 7: Normalize the BNPs for all attributes in order to find the crisp weights of the attributes. Normalization process is carried out using Eqn (11):

$$
w_{i}=\frac{B N P_{w i}}{\sum_{i=1}^{N} B N P_{w i}},
$$

where $B N P_{w i}$ is the $B N P$ value for attribute $i$ and $N$ is the number of attributes at the same evaluation dimension.

Step 8: Check consistency ratio. For this purpose, first TFNs in all pairwise comparison matrices are defuzzified. Then, the consistency ratio (CR) of the matrix including the defuzzified TFNs (i.e., crisp numbers) has been calculated adopting the approach proposed by Saaty (1980). If $\mathrm{CR}$ is lower than 0.1 , it can be concluded that the pairwise comparison matrix is sufficiently consistent.

\subsection{The fuzzy TOPSIS method}

TOPSIS, which was first developed by Hwang and Yoon (1981), is widely used for solving ranking problems. TOPSIS considers MCDM problems as a geometric system with $\mathrm{m}$ points (i.e., alternatives) in $\mathrm{n}$-dimensional space of criteria. The main idea behind TOPSIS is to choose the alternative, which has the shortest distance from the positive-ideal solution (PIS) (i.e., achieving the minimal gaps in each criterion) and the longest distance from the negative-ideal solution (NIS) (i.e., achieving the maximal levels in each criterion). In the TOPSIS method, an index, which defines the similarity to the PIS and the remoteness from the NIS, is calculated and an alternative with the maximum similarity to the PIS is chosen (Sun 2010). Although the traditional TOPSIS method is very popular and simple, it is often criticized for its inability to map decision makers' ambiguities, uncertainties, and vagueness in evaluating the performances of the alternatives with respect to several criteria. In order to overcome this problem and allow decision makers to formulate the decision problems where the available information is subjective, imprecise and incomplete, the TOPSIS method is extended with the fuzzy set theory (Dağdeviren et al. 2009). The main idea behind fuzzy TOPSIS is to use fuzzy numbers instead of crisp numbers in the evaluation process. In the literature, there are several fuzzy TOPSIS methods. In this study, Chen's (2000) method will be employed. Chen (2000) extends the TOPSIS method to fuzzy group decision making situations using TFNs and calculating crisp Euclidean distance between two fuzzy numbers. The steps of this method are briefly explained below (Chen 2000; Kahraman et al. 2010):

Step 1: Determine the weights of the evaluation/selection criteria. In this study, the weights are calculated using fuzzy AHP method.

Step 2: Consult decision makers and establish the fuzzy decision matrix, in which the alternatives are evaluated with respect to the evaluation criteria using the appropriate linguistic scale. The fuzzy decision matrix $\left(\tilde{D}=\left[\tilde{x}_{i j}\right]_{m x n}\right)$ is given by: 


$$
\tilde{D}_{k}=\left[\begin{array}{ccc}
\tilde{x}_{11 k} & \ldots & \tilde{x}_{1 n k} \\
\vdots & \ddots & \vdots \\
\tilde{x}_{m 1 k} & \ldots & \tilde{x}_{m n}
\end{array}\right],
$$

where $\tilde{D}_{k}$ is the fuzzy decision matrix constructed by the $k^{\text {th }}$ decision maker for evaluating the alternatives with respect to the criteria, $m$ is the number of alternatives, and $n$ is the number of criteria. During the evaluation process, linguistic scales are used.

Step 3: Aggregate the decision makers' fuzzy decision matrices by using the arithmetic mean. The aggregated TFN of all decision makers' fuzzy performance ratings in a certain case $\tilde{x}_{i j}=\left(l_{i j}, m_{i j}, u_{i j}\right)$ is calculated using Eqn (12):

$$
\tilde{x}_{i j}=\frac{1}{K} \sum_{i=1}^{K} \tilde{x}_{i j k}
$$

where $\tilde{x}_{i j k}$ is the fuzzy performance rating of alternative $i$ to criterion $j$ in the form of TFN specified by the $k^{\text {th }}$ decision maker, and $K$ is the number of decision makers.

Step 4: Normalize the fuzzy decision matrix using the linear scale transformation, which enables decision makers to transform TFNs into the closed interval $[0,1]$. The evaluation criterion may be either benefit criterion (i.e., the larger the rating, the greater the preference) or cost criterion (e.g., the smaller the rating, the greater the preference), and the normalization formulas are different for cost and benefit criteria. The normalized fuzzy decision matrix $\tilde{R}=\left[\tilde{r}_{i j}\right]_{m x n}$ can be computed by:

$\tilde{r}_{i j}=\left(\frac{l_{i j}}{u_{j}^{+}}, \frac{m_{i j}}{u_{j}^{+}}, \frac{u_{i j}}{u_{j}^{+}}\right)$and $u_{j}^{+}=\max _{i} u_{i j}$ for benefit criteria $;$

$\widetilde{r}_{i j}=\left(\frac{l_{j}^{-}}{u_{j}}, \frac{l_{j}^{-}}{m_{j}}, \frac{l_{j}^{-}}{l_{j}}\right)$ and $l_{j}^{-}=\max _{i} l_{j}$ for $\cos t$ criteria,

where $\tilde{r}_{i j}$ is the normalized value of $\tilde{x}_{i j}$.

Step 5: Compute the weighted normalized decision matrix $(\tilde{V})$ by multiplying the weights of the of the evaluation criteria $\left(\tilde{w}_{j}\right)$ by the elements of the normalized fuzzy decision matrix $\left(\tilde{r}_{i j}\right)$. The weighted normalized decision matrix $(\tilde{V})$ can be computed by:

$\widetilde{V}=\left[\widetilde{v}_{i j}\right]_{m \times n}$ and $\widetilde{v}_{j}=\widetilde{r}_{j} \times \widetilde{w}_{j} \quad i=1,2, \ldots, m, j=1,2, \ldots, n$,

where $\tilde{w}_{j}$ is the fuzzy weights of the criteria obtained from the fuzzy AHP computations.

Step 6: Determine the fuzzy PIS $\left(A^{+}\right)$and the fuzzy NIS $\left(A^{-}\right)$according to Eqns (16) and (17):

$$
A^{+}=\left(\widetilde{v}_{1}^{+}, \widetilde{v}_{2}^{+}, \widetilde{v}_{3}^{+}, \ldots, \widetilde{v}_{n}^{+}\right)
$$

$$
A^{-}=\left(\widetilde{v}_{1}^{-}, \widetilde{v}_{2}^{-}, \widetilde{v}_{3}^{-}, \ldots, \widetilde{v}_{n}^{-}\right),
$$

where $\tilde{v}_{j}^{+}=(1,1,1), \tilde{v}_{j}^{-}=(0,0,0)$, and $j=1,2,3$, $\ldots, n$.

Step 7: Calculate the distance of each alternative from $A^{+}$ and $A^{-}$using the following equations:

$$
\begin{aligned}
& d_{i}^{+}=\sum_{j=1}^{n} d\left(\tilde{v}_{j}, \tilde{v}_{j}^{+}\right) \quad i=1,2, \ldots, m ; \\
& d_{i}^{-}=\sum_{j=1}^{n} d\left(\tilde{v}_{j}, \tilde{v}_{j}^{-}\right) \quad i=1,2, \ldots, m,
\end{aligned}
$$

where $d(.,$.$) represents the distance between two fuzzy$ numbers, which is calculated according to the vertex method. For TFNs, $d(\tilde{x}, \tilde{z})$ can be computed by:

$d(\widetilde{x}, \widetilde{z})=\sqrt{\frac{1}{3}}\left[\left(l_{x}-l_{z}\right)^{2}+\left(m_{x}-m_{z}\right)^{2}+\left(u_{x}-u_{z}\right)^{2}\right]$.

Step 8: Compute the closeness coefficient of each alternative $\left(C C_{i}\right)$ to the ideal solution using Eqn (21):

$$
\boldsymbol{C}_{i}=\frac{d_{i}^{-}}{d_{i}^{-}+d_{i}^{+}} ; i=1,2, \ldots, m .
$$

Step 9: Rank the alternatives according to their relative closeness to the ideal solution in descending order. The best alternative is the one closest to the fuzzy PIS and farthest to the fuzzy NIS.

\section{Proposed integrated fuzzy MCGDM approach for supplier selection problem}

In this study, an integrated fuzzy MCGDM approach, which is composed of fuzzy AHP and fuzzy TOPSIS methods, is proposed for selecting the most appropriate supplier. The schematic diagram of the proposed approach for supplier selection is presented in Figure 3.

The proposed approach consists of four main stages, which are:

Stage 1 - Data gathering: In this stage, the decision making team, whose members are in charge of evaluating and/or selecting suppliers, is formed, the criteria that are considered by a construction company in the supplier selection process and alternative suppliers are determined, the decision hierarchy is developed, and the developed decision hierarchy is approved by the decision making team.

Stage 2 - Fuzzy AHP computations: In this phase, linguistic terms, which enable the decision making team members to define the relative importance weights of the supplier selection criteria in words or sentences, are determined, pairwise comparison matrices are formed, the decision making team members make their individual evaluations to determine the values of the elements of the 


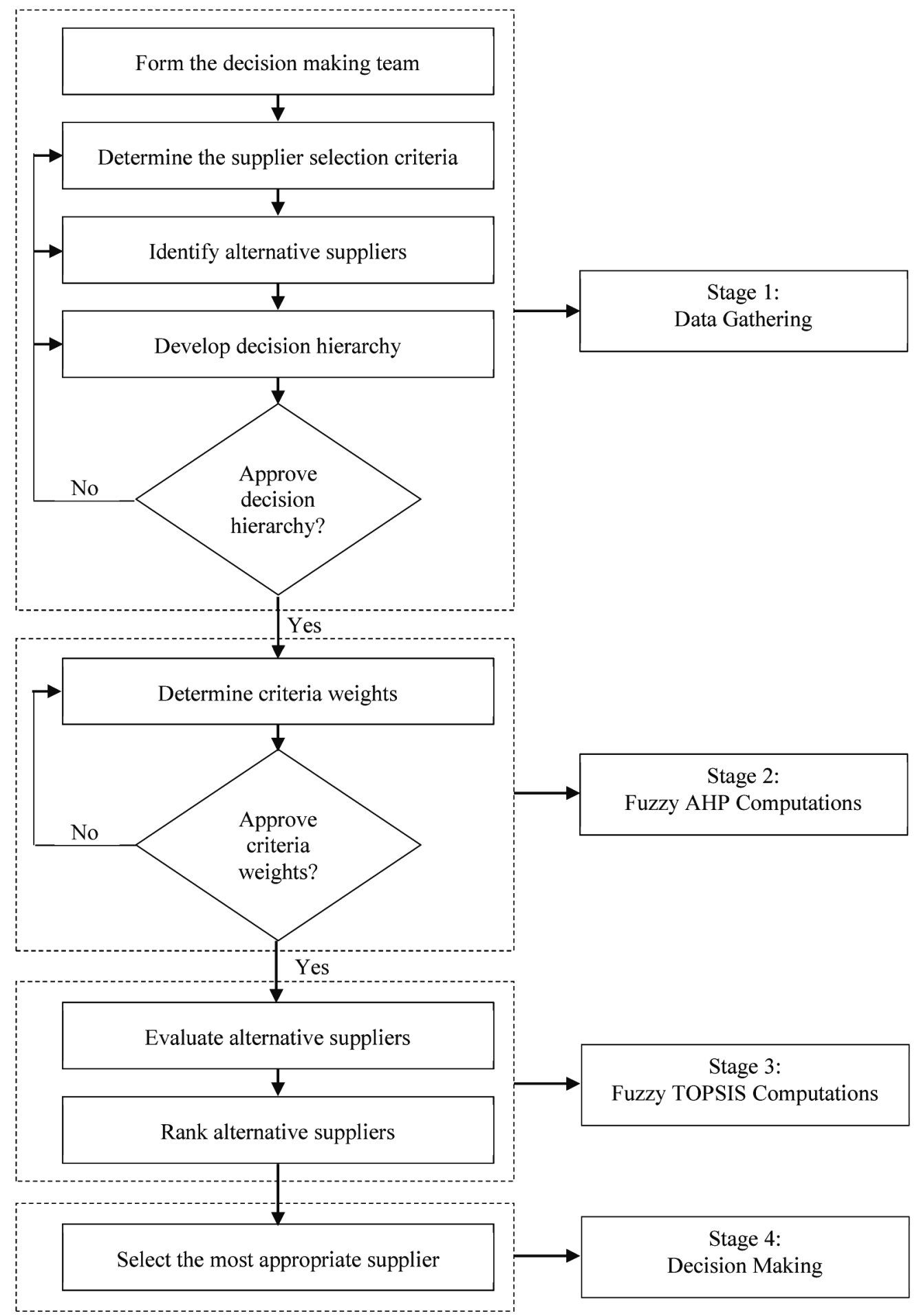

Fig. 3. Schematic diagram of the proposed approach for supplier selection 
Table 2. Linguistic variables for the importance weights of the criteria

\begin{tabular}{lccc}
\hline \multirow{2}{*}{ Linguistic Variables } & Crisp AHP Scale & \multicolumn{2}{c}{ Fuzzy AHP Scale } \\
\cline { 2 - 4 } & & TFNs & Reciprocal TFNs \\
\hline Equally Preferred (EqP) & 1 & $(1,1,1)$ & $(1,1,1)$ \\
\hline Equally to Moderately Preferred (Eq-MP) & 2 & $(1,2,3)$ & $(1 / 3,1 / 2,1)$ \\
\hline Moderately Preferred (MP) & 3 & $(2,3,4)$ & $(1 / 4,1 / 3,1 / 2)$ \\
\hline Moderately to Strongly Preferred (M-SP) & 4 & $(3,4,5)$ & $(1 / 5,1 / 4,1 / 3)$ \\
\hline Strongly Preferred (SP) & 5 & $(4,5,6)$ & $(1 / 6,1 / 5,1 / 4)$ \\
\hline Strongly to Very Strongly Preferred (S-VSP) & 6 & $(5,6,7)$ & $(1 / 7,1 / 6,1 / 5)$ \\
\hline Very Strongly Preferred (VSP) & 7 & $(6,7,8)$ & $(1 / 8,1 / 7,1 / 6)$ \\
\hline Very Strongly to Extremely Preferred (VS-ExP) & 8 & $(7,8,9)$ & $(1 / 9,1 / 8,1 / 7)$ \\
\hline Extremely Preferred (ExP) & 9 & $(8,9,9)$ & $(1 / 9,1 / 8,1 / 8)$ \\
\hline
\end{tabular}

pairwise comparison matrices using the linguistic terms determined for the importance weights of the criteria, the fuzzy AHP computations explained in "The Fuzzy AHP Method" section are carried out, the weights of the supplier selection criteria are determined, and the decision making team approves the calculated weights of the supplier selection criteria.

Stage 3 - Fuzzy TOPSIS computations: In this stage, linguistic terms, which enable the decision making team members to define the preference ratings of the alternative suppliers in words or sentences, are determined, the decision making team members individually evaluate the alternative suppliers using the linguistic terms determined for the preference rating of alternatives, the fuzzy TOPSIS computations explained in "The Fuzzy TOPSIS Method" section are carried out using the evaluations of the alternative suppliers and the weights of the supplier selection criteria determined in Stage 2, and the alternative suppliers are ranked.

Stage 4 -Decision making: In this phase, the most appropriate supplier is selected by the decision makers based on the ranking obtained from the fuzzy AHP and fuzzy TOPSIS computations.

\section{A numerical application of the proposed approach: case of rail supplier selection}

In order to illustrate how the proposed approach can be applied in a real situation, a case study is presented. In the present case, a general contractor, which predominantly undertakes international projects, intends to select rail supplier in an intercity railway project in Saudi Arabia. Since rail is one of the most important products used in the railway construction project, selecting the most appropriate rail supplier plays a critical role in completing the project in question successfully. The length of the studied project is $85 \mathrm{~km}$, the contract price is $€ 50.000 .000$, and the project duration is 18 months.

\subsection{Data gathering}

In this stage, first, the decision making team was formed. The decision making team included four civil engineers, who were highly experienced and responsible for selecting suppliers in the construction company. The decision making team stated that 8 criteria, namely, quality of the product $(\mathrm{C} 1)$, lead time $(\mathrm{C} 2)$, delivery performance $(\mathrm{C} 3)$, total cost of the product (C4), payment conditions (C5), communication with the supplier (C6), production capacity (C7) and technical expertise of the supplier (C8), were taken into account during the rail supplier selection process, shortlisted 5 suppliers (i.e., S1, S2, S3, S4, S5) for further consideration, and developed the decision hierarchy, which has 3 main levels (Goal, Criteria, and Alternatives) (see Fig. 4).

\subsection{Fuzzy AHP computations}

After the formation and approval of the decision hierarchy for supplier selection problem, the members of the

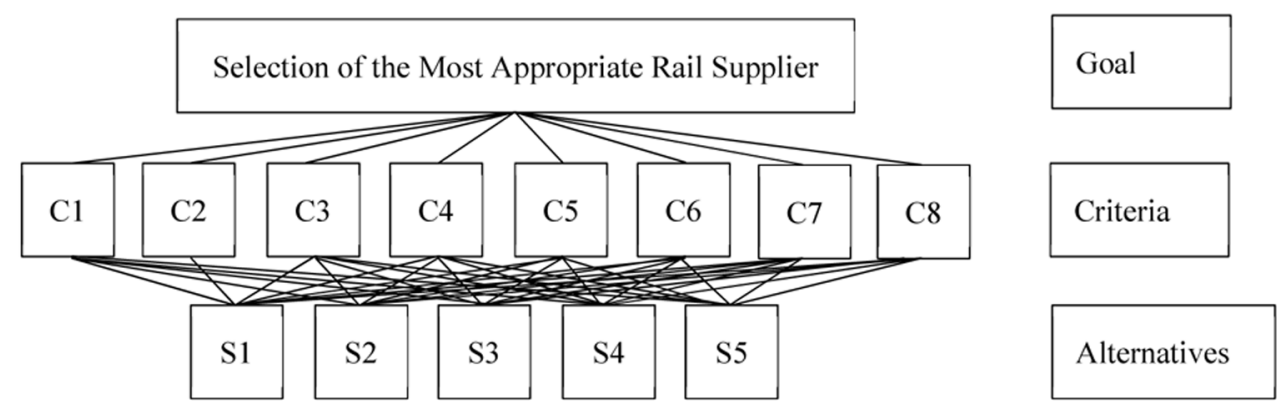

Fig. 4. Decision hierarchy of the supplier selection problem 
Table 3. Pairwise comparison matrices formed by 4 decision makers (DMs)

\begin{tabular}{|c|c|c|c|c|c|c|c|c|c|}
\hline \multirow{2}{*}{ DM\# } & \multirow{2}{*}{$\mathrm{C} \#$} & \multicolumn{8}{|c|}{ Supplier Selection Criteria (C\#) } \\
\hline & & $\mathrm{C} 1$ & $\mathrm{C} 2$ & $\mathrm{C} 3$ & $\mathrm{C} 4$ & $\mathrm{C} 5$ & C6 & $\mathrm{C} 7$ & $\mathrm{C} 8$ \\
\hline \multirow{8}{*}{ DM1 } & $\mathrm{C} 1$ & $\mathrm{EqP}$ & Eq-MP & M-SP & 1/M-SP & Eq-MP & MP & Eq-MP & Eq-MP \\
\hline & $\mathrm{C} 2$ & 1/Eq-MP & $\mathrm{EqP}$ & $\mathrm{SP}$ & 1/Eq-MP & $\mathrm{EqP}$ & M-SP & Eq-MP & Eq-MP \\
\hline & $\mathrm{C} 3$ & 1/M-SP & $1 / \mathrm{SP}$ & EqP & 1/VS-ExP & 1/M-SP & 1/Eq-MP & Eq-MP & 1/Eq-MP \\
\hline & $\mathrm{C} 4$ & M-SP & Eq-MP & VS-ExP & $\mathrm{EqP}$ & Eq-MP & VSP & S-VSP & EqP \\
\hline & $\mathrm{C} 5$ & 1/Eq-MP & $\mathrm{EqP}$ & M-SP & 1/Eq-MP & $\mathrm{EqP}$ & M-SP & Eq-MP & 1/M-SP \\
\hline & $\mathrm{C} 6$ & 1/MP & 1/M-SP & Eq-MP & 1/VSP & 1/M-SP & $\mathrm{EqP}$ & $\mathrm{EqP}$ & 1/M-SP \\
\hline & $\mathrm{C} 7$ & 1/Eq-MP & 1/Eq-MP & 1/Eq-MP & 1/S-VSP & 1/Eq-MP & $\mathrm{EqP}$ & $\mathrm{EqP}$ & 1/M-SP \\
\hline & $\mathrm{C} 8$ & 1/Eq-MP & 1/Eq-MP & Eq-MP & $\mathrm{EqP}$ & M-SP & M-SP & M-SP & $\mathrm{EqP}$ \\
\hline \multirow{8}{*}{ DM2 } & $\mathrm{C} 1$ & $\mathrm{EqP}$ & MP & Eq-MP & EqP & Eq-MP & M-SP & MP & Eq-MP \\
\hline & $\mathrm{C} 2$ & 1/MP & $\mathrm{EqP}$ & M-SP & 1/Eq-MP & MP & M-SP & SP & Eq-MP \\
\hline & $\mathrm{C} 3$ & 1/Eq-MP & 1/M-SP & $\mathrm{EqP}$ & 1/VS-ExP & 1/VS-ExP & Eq-MP & Eq-MP & 1/M-SP \\
\hline & $\mathrm{C} 4$ & $\mathrm{EqP}$ & Eq-MP & VS-ExP & $\mathrm{EqP}$ & M-SP & S-VSP & S-VSP & Eq-MP \\
\hline & $\mathrm{C} 5$ & 1/Eq-MP & 1/MP & VS-ExP & 1/M-SP & $\mathrm{EqP}$ & SP & MP & 1/M-SP \\
\hline & $\mathrm{C} 6$ & 1/M-SP & 1/M-SP & 1/Eq-MP & 1/S-VSP & $1 / \mathrm{SP}$ & $\mathrm{EqP}$ & $\mathrm{EqP}$ & 1/M-SP \\
\hline & $\mathrm{C} 7$ & 1/MP & 1/SP & 1/Eq-MP & 1/S-VSP & 1/MP & $\mathrm{EqP}$ & $\mathrm{EqP}$ & 1/M-SP \\
\hline & $\mathrm{C} 8$ & 1/Eq-MP & 1/Eq-MP & M-SP & 1/Eq-MP & M-SP & M-SP & M-SP & $\mathrm{EqP}$ \\
\hline \multirow{8}{*}{ DM3 } & $\mathrm{C} 1$ & $\mathrm{EqP}$ & M-SP & S-VSP & Eq-MP & VS-ExP & MP & Eq-MP & $\mathrm{EqP}$ \\
\hline & $\mathrm{C} 2$ & 1/M-SP & $\mathrm{EqP}$ & M-SP & 1/Eq-MP & MP & SP & EqP & 1/M-SP \\
\hline & $\mathrm{C} 3$ & 1/S-VSP & 1/M-SP & $\mathrm{EqP}$ & 1/M-SP & 1/Eq-MP & $\mathrm{EqP}$ & 1/Eq-MP & 1/S-VSP \\
\hline & $\mathrm{C} 4$ & 1/Eq-MP & Eq-MP & M-SP & $\mathrm{EqP}$ & MP & SP & 1/Eq-MP & Eq-MP \\
\hline & $\mathrm{C} 5$ & 1/VS-ExP & 1/MP & Eq-MP & 1/MP & $\mathrm{EqP}$ & Eq-MP & 1/M-SP & 1/S-VSP \\
\hline & $\mathrm{C} 6$ & 1/MP & $1 / \mathrm{SP}$ & $\mathrm{EqP}$ & $1 / \mathrm{SP}$ & 1/Eq-MP & $\mathrm{EqP}$ & 1/M-SP & 1/S-VSP \\
\hline & $\mathrm{C} 7$ & 1/Eq-MP & $\mathrm{EqP}$ & Eq-MP & Eq-MP & M-SP & M-SP & $\mathrm{EqP}$ & 1/SP \\
\hline & $\mathrm{C} 8$ & $\mathrm{EqP}$ & M-SP & S-VSP & 1/Eq-MP & S-VSP & S-VSP & SP & $\mathrm{EqP}$ \\
\hline \multirow{8}{*}{ DM4 } & $\mathrm{C} 1$ & $\mathrm{EqP}$ & $1 / \mathrm{SP}$ & EqP & 1/VS-ExP & 1/VS-ExP & 1/Eq-MP & $\mathrm{EqP}$ & $\mathrm{EqP}$ \\
\hline & $\mathrm{C} 2$ & SP & $\mathrm{EqP}$ & ExP & 1/Eq-MP & $\mathrm{EqP}$ & ExP & Eq-MP & Eq-MP \\
\hline & $\mathrm{C} 3$ & $\mathrm{EqP}$ & 1/ExP & $\mathrm{EqP}$ & 1/VS-ExP & 1/Eq-MP & $\mathrm{EqP}$ & $\mathrm{EqP}$ & 1/M-SP \\
\hline & $\mathrm{C} 4$ & VS-ExP & Eq-MP & VS-ExP & $\mathrm{EqP}$ & Eq-MP & VSP & VSP & $\mathrm{EqP}$ \\
\hline & $\mathrm{C} 5$ & VS-ExP & $\mathrm{EqP}$ & Eq-MP & 1/Eq-MP & $\mathrm{EqP}$ & MP & M-SP & 1/Eq-MP \\
\hline & $\mathrm{C} 6$ & Eq-MP & 1/ExP & $\mathrm{EqP}$ & 1/VSP & 1/MP & $\mathrm{EqP}$ & $\mathrm{EqP}$ & 1/Eq-MP \\
\hline & $\mathrm{C} 7$ & $\mathrm{EqP}$ & 1/Eq-MP & $\mathrm{EqP}$ & 1/VSP & 1/M-SP & $\mathrm{EqP}$ & $\mathrm{EqP}$ & EqP \\
\hline & $\mathrm{C} 8$ & $\mathrm{EqP}$ & 1/Eq-MP & M-SP & $\mathrm{EqP}$ & Eq-MP & Eq-MP & $\mathrm{EqP}$ & $\mathrm{EqP}$ \\
\hline
\end{tabular}

decision making team evaluated the relative importance weights of the supplier selection criteria on a 9 linguistic terms with respect to a fuzzy 9 level scale, which is presented in Table 2. In this scale, each membership function is defined by 3 parameters of a TFN (i.e., $\tilde{A}(l, m, u)$ ).

Having determined the linguistic scale, four decision makers (DM) individually formed their pairwise comparison matrix using this scale (see Table 3).

In order to calculate the importance weights of the supplier selection criteria, first linguistic evaluations of 4 DMs presented in Table 3 were transferred to the corresponding TFNs shown in Table 2, and then the final pairwise comparison matrix was obtained by aggregating the DMs' individual fuzzy evaluations. The elements of the synthetic pairwise comparison matrix were calculated by using the geometric mean method as suggested by Buckley (1985) (see Eqn (7)).

The final pairwise comparison matrix is presented in Table 4.

The fuzzy comparison values of each supplier selection criterion to all criteria at the same evaluation dimension were aggregated by using the geometric mean (see Eqn (8)). The weight of each supplier selection criterion was calculated using Eqn (9).

In order to compute the BNP values for the fuzzy weights of each supplier selection criterion, the COA method was applied (see Eqn (10)). After computing the BNP values for all criteria, they were normalized in or- 
Table 4. Final pairwise comparison matrix

\begin{tabular}{c|c|c|c|c|c|c|c|c}
\hline & $\mathrm{C} 1$ & $\mathrm{C} 2$ & $\mathrm{C} 3$ & $\mathrm{C} 4$ & $\mathrm{C} 5$ & $\mathrm{C} 6$ & $\mathrm{C} 7$ & $\mathrm{C} 8$ \\
\hline \multirow{2}{*}{ C1 } & $(1.00 ; 1.00$, & $(1.00,1.48$, & $(1.97,2.63$, & $(0.39,0.50$, & $(0.94,1.41$, & $(1.41,2.06$, & $(1.19,1.86$, & $(1.00,1.41$, \\
& $1.00)$ & $1.97)$ & $3.20)$ & $0.61)$ & $1.84)$ & $2.99)$ & $2.45)$ & $1.73)$ \\
\hline \multirow{2}{*}{ C2 } & $(0.51,0.68$, & $(1.00,1.00$, & $(4.12,5.18$, & $(0.33,0.5$, & $(1.41,1.73$, & $(4.12,5.18$, & $(1.41,2.11$, & $(0.67,1.19$, \\
& $1.00)$ & $1.00)$ & $6.06)$ & $1.00)$ & $2.00)$ & $6.06)$ & $2.71)$ & $1.73)$ \\
\hline \multirow{2}{*}{ C3 } & $(0.31,0.38$, & $(0.16,0.19$, & $(1.00,1.00$, & $(0.13,0.15$, & $(0.22,0.30$, & $(0.76,1.00$, & $(0.76,1.19$, & $(0.21,0.27$, \\
& $0.51)$ & $0.24)$ & $1.00)$ & $0.18)$ & $0.47)$ & $1.32)$ & $1.73)$ & $0.39)$ \\
\hline \multirow{2}{*}{ C4 } & $(1.63,2.00$, & $(1.00,2.00$, & $(5.66,6.73$, & $(1.00,1.00$, & $(1.57,2.63$, & $(5.18,6.19$, & $(2.66,3.35$, & $(1.00,1.41$, \\
& $2.59)$ & $3.00)$ & $7.77)$ & $1.00)$ & $3.66)$ & $7.20)$ & $4.45)$ & $1.73)$ \\
\hline \multirow{2}{*}{ C5 } & $(0.54,0.71$, & $(0.50,0.58$, & $(2.14,3.36$, & $(0.27,0.38$, & $(1.00,1.00$, & $(2.21,3.31$, & $(1.05,1.57$, & $(0.21,0.27$, \\
& $1.06)$ & $0.71)$ & $4.49)$ & $0.64)$ & $100)$ & $4.36)$ & $2.11)$ & $0.39)$ \\
\hline \multirow{2}{*}{ C6 } & $(0.33,0.49$, & $(0.16,0.19$, & $(0.76,1.00$, & $(0.14,0.16$, & $(0.23,0.30$, & $(1.00,1.00$, & $(0.67,0.71$, & $(0.21,0.27$, \\
& $0.71)$ & $0.24)$ & $1.32)$ & $0.19)$ & $0.45)$ & $1.00)$ & $0.76)$ & $0.39)$ \\
\hline \multirow{2}{*}{ C7 } & $(0.41,0.54$, & $(0.37,0.47$, & $(0.58,0.84$, & $(0.22,0.30$, & $(0.47,0.64$, & $(1.32,1.41$, & $(1.00,1.00$, & $(0.29,0.33$, \\
& $0.84)$ & $0.71)$ & $1.32)$ & $0.38)$ & $0.96)$ & $1.50)$ & $1.00)$ & $0.41)$ \\
\hline \multirow{2}{*}{ C8 } & $(0.58,0.71$, & $(0.58,0.84$, & $(2.59,3.72$, & $(0.58,0.71$, & $(2.59,3.72$, & $(2.59,3.72$, & $(2.45,2.99$, & $(1.00,1.00$, \\
& $1.00)$ & $1.50)$ & $4.79)$ & $1.00)$ & $4.79)$ & $4.79)$ & $3.50)$ & $1.00)$ \\
\hline
\end{tabular}

Table 5. Weights of the supplier selection criteria

\begin{tabular}{l|c|c|c|c}
\hline \multicolumn{1}{c|}{ Supplier Selection Criteria } & Fuzzy Weights & BNP & Crisp Weights & Rank \\
\hline Quality of the product & $(0.08,0.14,0.24)$ & 0.16 & 0.14 & 4 \\
Lead time & $(0.09,0.16,0.28)$ & 0.18 & 0.16 & 3 \\
Delivery performance & $(0.03,0.04,0.08)$ & 0.05 & 0.04 & 7 \\
Total cost of the product & $(0.16,0.27,0.44)$ & 0.29 & 0.26 & 0.10 \\
Payment conditions & $(0.06,0.10,0.18)$ & 0.11 & 0.04 & 5 \\
Communication with the supplier & $(0.03,0.04,0.07)$ & 0.05 & 0.06 & 8 \\
Production capacity & $(0.04,0.06,0.11)$ & 0.07 & 0.18 & 6 \\
Technical expertise of the supplier & $(0.10,0.17,0.30)$ & 0.19 & & 2 \\
\hline
\end{tabular}

der to find the crisp weights (see Eqn (11)). The fuzzy weights, BNP values, and the crisp weights of all supplier selection criteria are presented in Table 5.

As seen in Table 5, the first three most important criteria for the evaluation of rail suppliers for the studied construction company are total cost of the product (0.26), technical expertise of the supplier (0.18), and lead time (0.16). On the other hand, the two least important criteria are delivery performance $(0.05)$ and communication with the supplier (0.05).

It is necessary to check the consistency ratio of the comparison after aggregating group decisions. For this purpose, each TFN in the pairwise comparison matrix was defuzzified using the COA method, and the CR of the defuzzified matrix was calculated and checked whether CR is smaller than 0.10 or not. The CR of the pairwise comparison matrix was found to be 0.057 , which indicates that the judgment matrix is consistent and the weights can be used in the selection process.

\subsection{Fuzzy TOPSIS computations}

Having calculated the fuzzy weights of the supplier selection criteria via the fuzzy AHP method, the members of the decision making team evaluated the performances of the alternative suppliers with respect to the criteria based on a linguistic scale presented in Table 6. In this scale, each membership function is defined by 3 parameters of a TFN (i.e., $\tilde{A}(l, m, u))$.

Table 6. Linguistic terms for the preference rating of the alternatives

\begin{tabular}{lc}
\hline \multicolumn{1}{c}{ Linguistic Variables } & Corresponding TFNs \\
\hline Very Bad (VB) & $(1,1,2)$ \\
Very Bad to Bad (VB-B) & $(1,2,3)$ \\
Bad (B) & $(2,3,4)$ \\
Bad to Average (B-A) & $(3,4,5)$ \\
Average (A) & $(4,5,6)$ \\
Average to Good (A-G) & $(5,6,7)$ \\
Good (G) & $(6,7,8)$ \\
Good to Very Good (G-VG) & $(7,8,9)$ \\
Very Good (VG) & $(8,9,9)$ \\
\hline
\end{tabular}

After determining the linguistic terms for the preference rating of the alternatives, four members of the decision making team (DMs) individually evaluated the alternatives with respect to the selection criteria using this scale and formed the fuzzy decision matrix (see Table 7). 
Table 7. Performance evaluations of the alternatives

\begin{tabular}{|c|c|c|c|c|c|c|c|c|c|}
\hline \multirow{2}{*}{ DM \# } & \multirow{2}{*}{ Alternatives } & \multicolumn{8}{|c|}{ Assessment Criteria } \\
\hline & & $\mathrm{C} 1$ & $\mathrm{C} 2$ & $\mathrm{C} 3$ & $\mathrm{C} 4$ & $\mathrm{C} 5$ & C6 & C7 & $\mathrm{C} 8$ \\
\hline \multirow{5}{*}{ DM-1 } & A1 & A-G & $\mathrm{A}$ & G & $\mathrm{A}$ & G & VG & B-A & G-VG \\
\hline & A2 & VG & $\mathrm{G}$ & B-A & B & B-A & B-A & $\mathrm{G}$ & VG \\
\hline & A3 & G-VG & A-G & $\mathrm{B}$ & A & $\mathrm{B}$ & B-A & B-A & G-VG \\
\hline & A4 & G-VG & A & G & G & B-A & A-G & $\mathrm{A}$ & A-G \\
\hline & A5 & $\mathrm{G}$ & G-VG & $\mathrm{A}$ & B-A & $\mathrm{B}$ & $\mathrm{A}$ & G-VG & $\mathrm{A}$ \\
\hline \multirow{5}{*}{ DM-2 } & A1 & $\mathrm{G}$ & B & G-VG & A-G & A-G & VG & A & $\mathrm{G}$ \\
\hline & A2 & VG & $\mathrm{G}$ & G-VG & B-A & B-A & VB-B & G-VG & G-VG \\
\hline & A3 & VG & A-G & B & $\mathrm{A}$ & $\mathrm{G}$ & $\mathrm{A}$ & B-A & A-G \\
\hline & A4 & A-G & B & A-G & $\mathrm{G}$ & A-G & G-VG & B-A & $\mathrm{A}$ \\
\hline & A5 & A-G & $\mathrm{G}-\mathrm{VG}$ & A & B-A & $\mathrm{G}$ & B-A & G-VG & $\mathrm{A}$ \\
\hline \multirow{5}{*}{ DM-3 } & $\mathrm{A} 1$ & A-G & $\mathrm{B}$ & G-VG & A-G & $\mathrm{G}$ & VG & $\mathrm{B}$ & $\mathrm{G}$ \\
\hline & A2 & VG & A & A & B-A & B-A & B-A & G & G-VG \\
\hline & A3 & G-VG & A-G & B & A-G & A & B-A & $\mathrm{A}$ & G \\
\hline & A4 & G & B & $\mathrm{G}$ & G & A-G & G-VG & B-A & A-G \\
\hline & A5 & A-G & G-VG & B-A & A & A & B & $\mathrm{G}$ & A-G \\
\hline \multirow{5}{*}{ DM-4 } & $\mathrm{A} 1$ & $\mathrm{G}$ & B-A & $\mathrm{G}$ & G-VG & G-VG & G-VG & B-A & $\mathrm{G}$ \\
\hline & $\mathrm{A} 2$ & VG & $\mathrm{G}$ & B-A & B-A & A-G & B-A & A-G & G-VG \\
\hline & A3 & A-G & A-G & $\mathrm{B}$ & $\mathrm{G}$ & A-G & B-A & B & $\mathrm{G}$ \\
\hline & A4 & $\mathrm{G}$ & B-A & A-G & G-VG & $\mathrm{G}-\mathrm{VG}$ & $\mathrm{G}$ & A & A-G \\
\hline & A5 & A-G & G-VG & B-A & A-G & A-G & B & G & A \\
\hline
\end{tabular}

Table 8. Aggregated evaluations of the alternatives

\begin{tabular}{|c|c|c|c|c|c|c|c|c|}
\hline & $\mathrm{C} 1$ & $\mathrm{C} 2$ & C3 & $\mathrm{C} 4$ & C5 & C6 & C7 & $\mathrm{C} 8$ \\
\hline A1 & $\begin{array}{c}(5.50,6.50 \\
7.50)\end{array}$ & $\begin{array}{c}(2.75,3.75 \\
4.75)\end{array}$ & $\begin{array}{c}(6.50,7.50 \\
8.50)\end{array}$ & $\begin{array}{c}(5.25,6.25 \\
7.25)\end{array}$ & $\begin{array}{c}(6.00,7.00, \\
8.00)\end{array}$ & $\begin{array}{c}(7.75,8.75 \\
9.00)\end{array}$ & $\begin{array}{c}(3.00,4.00 \\
5.00)\end{array}$ & $\begin{array}{c}(6.25,7.25, \\
8.25)\end{array}$ \\
\hline A2 & $\begin{array}{c}(8.00,9.00 \\
9.00)\end{array}$ & $\begin{array}{c}(5.50,6.50 \\
7.50)\end{array}$ & $\begin{array}{c}(4.25,5.25, \\
6.25)\end{array}$ & $\begin{array}{c}(2.75,3.75 \\
4.75)\end{array}$ & $\begin{array}{c}(3.50,4.50 \\
5.50)\end{array}$ & $\begin{array}{c}(2.50,3.50 \\
4.50)\end{array}$ & $\begin{array}{c}(6.00,7.00 \\
8.00)\end{array}$ & $\begin{array}{c}(7.25,8.25 \\
9.00)\end{array}$ \\
\hline A3 & $\begin{array}{c}(6.75,7.75 \\
8.50)\end{array}$ & $\begin{array}{c}(5.00,6.00) \\
7.00)\end{array}$ & $\begin{array}{c}(2.00,3.00 \\
4.00)\end{array}$ & $\begin{array}{c}4.75,5.75 \\
6.75)\end{array}$ & $\begin{array}{c}(4.25,5.25 \\
6.25)\end{array}$ & $\begin{array}{c}(3.25,4.25 \\
5.25)\end{array}$ & $\begin{array}{c}(3.00,4.00 \\
5.00)\end{array}$ & $\begin{array}{c}(6.00,7.00, \\
8.00)\end{array}$ \\
\hline A4 & $\begin{array}{c}(6.00,7.00 \\
8.00)\end{array}$ & $\begin{array}{c}(2.75,3.75 \\
4.75)\end{array}$ & $\begin{array}{c}(5.50,6.50 \\
7.50)\end{array}$ & $\begin{array}{c}(6.25,7.25 \\
8.25)\end{array}$ & $\begin{array}{c}(5.00,6.00, \\
7.00)\end{array}$ & $\begin{array}{c}(6.25,7.25 \\
8.25)\end{array}$ & $\begin{array}{c}(3.50,4.50 \\
5.50)\end{array}$ & $\begin{array}{c}(4.75,5.75, \\
6.75)\end{array}$ \\
\hline A5 & $\begin{array}{c}(5.25,6.25 \\
7.25)\end{array}$ & $\begin{array}{c}(7.00,8.00 \\
9.00)\end{array}$ & $\begin{array}{c}(3.50,4.50 \\
5.50)\end{array}$ & $\begin{array}{c}(3.75,4.75 \\
5.75)\end{array}$ & $\begin{array}{c}(4.25,5.25 \\
6.25)\end{array}$ & $\begin{array}{c}2.75,3.75 \\
4.75)\end{array}$ & $\begin{array}{c}6.50,7.50 \\
8.50)\end{array}$ & $\begin{array}{c}(4.25,5.25, \\
6.25)\end{array}$ \\
\hline W & $\begin{array}{c}(0.08,0.14 \\
0.24)\end{array}$ & $\begin{array}{c}(0.09,0.16 \\
0.28)\end{array}$ & $\begin{array}{c}(0.03,0.04 \\
0.08)\end{array}$ & $\begin{array}{c}(0.16,0.27 \\
0.44)\end{array}$ & $\begin{array}{c}(0.06,0.10 \\
0.18)\end{array}$ & $\begin{array}{c}(0.03,0.04 \\
0.07)\end{array}$ & $\begin{array}{c}(0.04,0.06 \\
0.11)\end{array}$ & $\begin{array}{c}(0.10,0.17, \\
0.30)\end{array}$ \\
\hline
\end{tabular}

In order to aggregate the decision makers' preference ratings, first linguistic evaluations of $4 \mathrm{DMs}$ presented in Table 7 were transferred to the corresponding TFNs displayed in Table 6, and then the aggregated preference ratings of the alternatives were calculated using Eqn (12). The aggregated evaluations of the alternatives with respect to the criteria and the fuzzy importance weights of the criteria obtained from the fuzzy AHP computations are shown in Table 8.

After aggregating the evaluations of 4 DMs, the fuzzy decision matrix was normalized using Eqn (13). In this study, all supplier selection criteria are considered as benefit criteria (i.e., the larger the rating, the greater the preference). The normalized fuzzy decision matrix is presented in Table 9.
Having normalized the fuzzy decision matrix, the weighted fuzzy decision matrix was constructed. The elements of this matrix were calculated using Eqn (15) and the results are presented in Table 10. The fuzzy importance weights of the criteria derived from the fuzzy AHP computations were used to form the weighted fuzzy decision matrix.

In the next step, the fuzzy PIS $\left(A^{+}\right)$and the fuzzy NIS ( $\left.\mathrm{A}^{-}\right)$were determined as expressed in Eqns (16) and (17). Then, the distances from $A^{+}\left(d_{i}^{+}\right)$and $A^{-}\left(d_{i}^{-}\right)$were calculated using Eqns (18)-(20), and the closeness coefficients of the alternatives $\left(C C_{i}\right)$ were computed using Eqn (21). The results of these computations and the final ranking of the alternatives are displayed in Table 11. 
Table 9. Normalized fuzzy decision matrix

\begin{tabular}{|c|c|c|c|c|c|c|c|c|}
\hline & $\mathrm{C} 1$ & $\mathrm{C} 2$ & C3 & $\mathrm{C} 4$ & C5 & C6 & C7 & C8 \\
\hline A1 & $\begin{array}{c}(0.61,0.72 \\
0.83)\end{array}$ & $\begin{array}{c}(0.31,0.42 \\
0.53)\end{array}$ & $\begin{array}{c}(0.76,0.88 \\
1.00)\end{array}$ & $\begin{array}{c}(0.64,0.76 \\
0.88)\end{array}$ & $\begin{array}{c}(0.75,0.88 \\
1.00)\end{array}$ & $\begin{array}{c}(0.86,0.97 \\
1.00)\end{array}$ & $\begin{array}{c}(0.35,0.47 \\
0.59)\end{array}$ & $\begin{array}{c}(0.69,0.81, \\
0.92)\end{array}$ \\
\hline $\mathrm{A} 2$ & $\begin{array}{c}(0.89,1.00 \\
1.00)\end{array}$ & $\begin{array}{c}(0.61,0.72 \\
0.83)\end{array}$ & $\begin{array}{c}(0.50,0.62 \\
0.74)\end{array}$ & $\begin{array}{c}(0.33,0.45 \\
0.58)\end{array}$ & $\begin{array}{c}(0.44,0.56 \\
0.69)\end{array}$ & $\begin{array}{c}(0.28,0.39 \\
0.50)\end{array}$ & $\begin{array}{c}(0.71,0.82 \\
0.94)\end{array}$ & $\begin{array}{c}(0.81,0.92 \\
1.00)\end{array}$ \\
\hline A 3 & $\begin{array}{c}(0.75,0.86 \\
0.94)\end{array}$ & $\begin{array}{c}(0.56,0.67 \\
0.78)\end{array}$ & $\begin{array}{c}(0.24,0.35 \\
0.47)\end{array}$ & $\begin{array}{c}(0.58,0.70 \\
0.82)\end{array}$ & $\begin{array}{c}(0.53,0.66 \\
0.78)\end{array}$ & $\begin{array}{c}(0.36,0.47 \\
0.58)\end{array}$ & $\begin{array}{c}(0.35,0.47 \\
0.59)\end{array}$ & $\begin{array}{c}(0.67,0.78 \\
0.89)\end{array}$ \\
\hline A4 & $\begin{array}{c}(0.67,0.78 \\
0.89)\end{array}$ & $\begin{array}{c}(0.31,0.42 \\
0.53)\end{array}$ & $\begin{array}{c}(0.65,0.76 \\
0.88)\end{array}$ & $\begin{array}{c}(0.76,0.88 \\
1.00)\end{array}$ & $\begin{array}{c}(0.63,0.75 \\
0.88)\end{array}$ & $\begin{array}{c}(0.69,0.81 \\
0.92)\end{array}$ & $\begin{array}{c}(0.41,0.53 \\
0.65)\end{array}$ & $\begin{array}{c}(0.53,0.64 \\
0.75)\end{array}$ \\
\hline A5 & $\begin{array}{c}(0.58,0.69 \\
0.81)\end{array}$ & $\begin{array}{c}(0.78,0.89 \\
1.00)\end{array}$ & $\begin{array}{c}(0.41,0.53 \\
0.65)\end{array}$ & $\begin{array}{c}(0.45,0.58 \\
0.70)\end{array}$ & $\begin{array}{c}(0.53,0.66 \\
0.78)\end{array}$ & $\begin{array}{c}(0.31,0.42 \\
0.53)\end{array}$ & $\begin{array}{c}(0.76,0.88 \\
1.00)\end{array}$ & $\begin{array}{c}(0.47,0.58, \\
0.69)\end{array}$ \\
\hline
\end{tabular}

Table 10. Weighted fuzzy decision matrix

\begin{tabular}{|c|c|c|c|c|c|c|c|c|}
\hline & $\mathrm{C} 1$ & $\mathrm{C} 2$ & C3 & $\mathrm{C} 4$ & C5 & C6 & C7 & C8 \\
\hline A1 & $\begin{array}{c}(0.05,0.10 \\
0.20)\end{array}$ & $\begin{array}{c}(0.03,0.07 \\
0.15) \\
\end{array}$ & $\begin{array}{c}(0.02,0.04 \\
0.08)\end{array}$ & $\begin{array}{c}(0.10,0.20, \\
0.39)\end{array}$ & $\begin{array}{c}(0.04,0.09 \\
0.18)\end{array}$ & $\begin{array}{c}0.02,0.04 \\
0.07) \\
\end{array}$ & $\begin{array}{c}(0.01,0.03 \\
0.06)\end{array}$ & $\begin{array}{c}(0.07,0.14, \\
0.28)\end{array}$ \\
\hline A2 & $\begin{array}{c}(0.07,0.14 \\
0.24)\end{array}$ & $\begin{array}{c}(0.06,0.12 \\
0.24)\end{array}$ & $\begin{array}{c}(0.01,0.03 \\
0.06)\end{array}$ & $\begin{array}{c}(0.05,0.12 \\
0.25)\end{array}$ & $\begin{array}{c}(0.03,0.06 \\
0.12)\end{array}$ & $\begin{array}{c}(0.01,0.02 \\
0.04)\end{array}$ & $\begin{array}{c}(0.03,0.05 \\
0.10)\end{array}$ & $\begin{array}{c}(0.08,0.16 \\
0.30)\end{array}$ \\
\hline A3 & $\begin{array}{c}(0.06,0.12 \\
0.23)\end{array}$ & $\begin{array}{c}(0.05,0.11 \\
0.22)\end{array}$ & $\begin{array}{c}(0.01,0.02 \\
0.04)\end{array}$ & $\begin{array}{c}(0.09,0.19 \\
0.36)\end{array}$ & $\begin{array}{c}(0.03,0.07 \\
0.14)\end{array}$ & $\begin{array}{c}(0.01,0.02 \\
0.04)\end{array}$ & $\begin{array}{c}(0.01,0.03 \\
0.06)\end{array}$ & $\begin{array}{c}(0.07,0.14, \\
0.27)\end{array}$ \\
\hline A4 & $\begin{array}{c}(0.05,0.11, \\
0.21)\end{array}$ & $\begin{array}{c}(0.03,0.07 \\
0.15)\end{array}$ & $\begin{array}{c}(0.02,0.03, \\
0.07)\end{array}$ & $\begin{array}{c}(0.12,0.24, \\
0.44)\end{array}$ & $\begin{array}{c}(0.04,0.07 \\
0.15)\end{array}$ & $\begin{array}{c}(0.02,0.03 \\
0.07)\end{array}$ & $\begin{array}{c}(0.02,0.03 \\
0.07)\end{array}$ & $\begin{array}{c}(0.06,0.11, \\
0.23)\end{array}$ \\
\hline A5 & $\begin{array}{c}(0.05,0.10 \\
0.19)\end{array}$ & $\begin{array}{c}(0.07,0.15 \\
0.28)\end{array}$ & $\begin{array}{c}(0.01,0.02 \\
0.05)\end{array}$ & $\begin{array}{c}(0.07,0.15 \\
0.31)\end{array}$ & $\begin{array}{c}(0.03,0.07 \\
0.14)\end{array}$ & $\begin{array}{c}(0.01,0.02 \\
0.04)\end{array}$ & $\begin{array}{c}(0.03,0.06 \\
0.11)\end{array}$ & $\begin{array}{c}(0.05,0.10 \\
0.21)\end{array}$ \\
\hline
\end{tabular}

Table 11. Distances, closeness coefficients, and final ranking of the alternatives

\begin{tabular}{c|c|c|c|c}
\hline Alternatives & $d_{i}^{+}$ & $d_{i}^{-}$ & $C C_{i}$ & Ranking \\
\hline A1 & 7.20 & 0.93 & 0.114 & 1 \\
A2 & 7.22 & 0.90 & 0.111 & 3 \\
A3 & 7.23 & 0.90 & 0.110 & 4 \\
A4 & 7.21 & 0.92 & 0.113 & 2 \\
A5 & 7.25 & 0.88 & 0.108 & 5 \\
\hline
\end{tabular}

Based on the results presented in Table 11, it can be seen that the closeness coefficients $\left(C C_{i}\right)$ of the alternatives are very close to each other and there are only slight differences between them. The decision makers stated that since the rail supplier alternatives were selected from the shortlist, it was very reasonable that their performance scores did not significantly vary. The final ranking of the alternatives in descending order was found as: A1, A4, A2, A3, and A5.

In the studied construction company, the decision makers decided to work with A1 in the railway project in question and reported that they had not experienced any severe problems during the construction phase. Company management found the proposed approach satisfactory and implementable in future supplier selection problems.

\section{Conclusions}

Materials comprise a large proportion of the total cost of a construction project and the unavailability of right materials in the right quantities and quality on site when needed is one of the most commonly experienced causes of delays in construction projects. Thus, supplier selection is a strategic issue and has significant impacts on the overall project performance. Contractors generally tend to select suppliers based on their past experiences. However, this practice may cause selecting wrong suppliers, which in turn bring about quality problems, cost overruns, delays, environmental problems, etc. Selecting the right supplier from several possible alternatives is not an easy task for contractors as this decision is affected by several quantitative and qualitative criteria, most of which are compromising and conflicting. Moreover, supplier selection is generally made by multiple decision makers, who may have different points of views and prefer to specify their preferences by linguistic variables. An effective evaluation approach should allow synthesizing the subjective evaluations of different decision makers.

This study proposes an integrated fuzzy MCGDM approach, which aims to help contractors for the selection of the most appropriate rail supplier among a set of available alternatives considering several compromising and conflicting criteria simultaneously. The proposed approach enables decision makers to express their preferences by linguistic variables using TFNs and allows com- 
bining subjective judgements of different individuals by a scientific method in order to come to a final decision. In this study, fuzzy AHP and fuzzy TOPSIS are employed together. Fuzzy AHP is used to analyse the structure of the supplier selection problem and to determine the weights of the identified criteria, whereas fuzzy TOPSIS is employed to determine the priorities of the alternative suppliers based on the criteria weights obtained from fuzzy AHP.

Supplier selection problem could have been solved by using only fuzzy AHP or fuzzy TOPSIS. These methods have their own strengths and weaknesses. One of the strengths of fuzzy AHP is that it develops a decision hierarchy (i.e., goal, main criteria, sub-criteria, alternatives, etc. and allows calculating the relative importance weights of the criteria and alternatives. On the other hand, fuzzy TOPSIS does not provide this structuring possibility. In the fuzzy AHP method, the relative importance weights of the criteria are determined via pairwise comparisons constructed by decision makers. On the other hand, it is not clear how these weights should be obtained in fuzzy TOPSIS. Two of the most important weaknesses of fuzzy AHP are the need for a great number of pairwise comparisons and the artificial limitation of the use of 9-point fuzzy scale. On the contrary, fuzzy TOPSIS needs only the decision makers' evaluations with respect to identified selection criteria using linguistic terms. In this study, fuzzy AHP and fuzzy TOPSIS are used together in order to combine the strengths of both methods.

The proposed approach was applied to a problem of selecting the most appropriate rail supplier to be worked with in an international railway construction project in order to illustrate how this approach can be used in a real life problem. In the studied construction company, the decision makers decided to work with the rail supplier ranked first (i.e., A1) and stated that they had not encountered any severe problems regarding the supply of rail. Company management stated that they could employ the proposed approach in future supplier selection problems.

In spite of the advantages of the proposed approach, there are also some limitations. First, there is no readymade software that facilitates the computation process for decision makers and all computations should be made by hand. Second, the construction professionals may not be aware of these methods. The development of user friendly ready-made software might encourage professionals to employ the proposed model in their decision making process.

In future studies, different fuzzy MCGDM methods, e.g., VIKOR, DEMATEL, COPRAS, ELECTRE, PROMETHEE, etc. can be employed to solve the same supplier selection problem and the results can be compared with the findings of this study. This is one of the future directions of this research.

\section{References}

Abdullah, L.; Zulkifli, N. 2015. Integration of fuzzy AHP and interval type-2 fuzzy DEMATEL: An application to human resource management, Expert Systems with Applications 42(9): 4397-4409.

https://doi.org/10.1016/j.eswa.2015.01.021

Akintoye, A. 1995. Just in time application and implementation for building materials management, Construction Management and Economics 13: 105-113. https://doi.org/10.1080/01446199500000013

Aretoulis, G. N.; Kalfakakou, G. P.; Striagka, F. Z. 2010. Construction material supplier selection under multiple criteria, Operational Research 10(2): 209-230. https://doi.org/10.1007/s12351-009-0065-3

Ballard, G.; Howell, G. 1997. Toward construction JIT, in L. Alarcón (Ed.). Lean construction. Rotterdam: A. A. Balkema. https://doi.org/10.4324/9780203345825 Toward_construction_JIT

Ballard, G.; Howell, G. 1998. What kind of production is construction, in $6^{\text {th }}$ Annual Conference of the International Group for Lean Construction, 13-15 August 1998, Guarujá, Brazil.

Benton, W. C.; McHenry, L. F. 2010. Construction purchasing and supply chain management. New York: McGraw-Hill.

Buckley, J. J. 1985. Fuzzy hierarchical analysis, Fuzzy Sets and Systems 17(3): 233-247. https://doi.org/10.1016/0165-0114(85)90090-9

Chang, D. Y. 1996. Applications of the extent analysis method on fuzzy AHP, European Journal of Operational Research 95: 649-655. https://doi.org/10.1016/0377-2217(95)00300-2

Chen, C. T. 2000. Extensions of the TOPSIS for group decisionmaking under fuzzy environment, Fuzzy Sets and Systems 114: 1-9. https://doi.org/10.1016/S0165-0114(97)00377-1

Chen, X.; Zhou, X. F.; Zhang, Y. 2011. Research on building engineering materials supplier selection based on ANP method, Key Engineering Materials 474-476: 2089-2094. https://doi.org/10.4028/www.scientific.net/KEM.474476.2089

Choy, K. L.; Lee, W. B.; Lo, V. 2003. Design of an intelligent supplier relationship management system: A hybrid case based neural network approach, Expert Systems with Applications 24(2): 225-237. https://doi.org/10.1016/S0957-4174(02)00151-3

Dağdeviren, M.; Yavuz, S.; Kılınç, N. 2009. Weapon selection using the AHP and TOPSIS methods under fuzzy environment, Expert Systems with Applications 36: 8143-8151. https://doi.org/10.1016/j.eswa.2008.10.016

Donyavi, S.; Flanagan, R. 2009. The impact of effective material management on construction site performance for small and medium sized construction enterprises, in $25^{\text {th }}$ Annual ARCOM Conference, 7-9 September 2009, Nottingham, UK.

Efe, B. 2016. An integrated fuzzy multi criteria group decision making approach for ERP system selection, Applied Soft Computing 38: 106-117. https://doi.org/10.1016/j.asoc.2015.09.037

Formoso, C. T.; Revelo, V. H. 1999. Improving the materials supply system in small-sized building firms, Automation in Construction 8(6): 663-670.

https://doi.org/10.1016/S0926-5805(98)00112-5

Ghodsypour, S. H.; O’Brien, C. 1998. A decision support system for supplier selection using an integrated analytical hierarchy process and linear programming, International Journal of Production Economics 56-67(20): 199-212.

Hadikusumo, B. H. W.; Petchpong, S.; Charoenngam, C. 2005. Construction material procurement using internet-based agent system, Automation in Construction 14(6): 736-749. https://doi.org/10.1016/j.autcon.2005.01.004 
Halpin, D. W.; Senior, B. A. 2011. Construction management. $4^{\text {th }}$ ed. Hoboken: John Wiley \& Sons.

Ho, C.; Nguyen, P. 2007. Supplier evaluation and selection criteria in the construction industry of Taiwan and Vietnam, International Journal of Information and Management Sciences 18(4): 403-426.

Ho, W.; Xu, X.; Dey, P. K. 2010. Multi-criteria decision making approaches for supplier evaluation and selection: a literature review, European Journal of Operational Research 202(1): 16-24. https://doi.org/10.1016/j.ejor.2009.05.009

Hsieh, T. Y.; Lu, S. T.; Tzeng, G. H. 2004. Fuzzy MCDM approach for planning and design tenders selection in public office buildings, International Journal of Project Management 22(7): 573-584. https://doi.org/10.1016/j.ijproman.2004.01.002

Ibn-Homaid, N. T. 2002. A comparative evaluation of construction and manufacturing materials management, International Journal of Project Management 20: 263-270. https://doi.org/10.1016/S0263-7863(01)00013-8

Guan, J.; Zhang, Z.; Wu, Y. 2013. Using fuzzy matter-element model and triangular fuzzy AHP method to select the international construction project material suppliers, Applied Mechanics and Materials 357-360: 2277-2281.

https://doi.org/10.4028/www.scientific.net/AMM.357-360.2277

Hwang, C. L.; Yoon, K. 1981. Multiple attribute decision making: methods and applications, a state of the art survey. New York: Springer-Verlag. https://doi.org/10.1007/978-3-642-48318-9

Junior, F. R. L.; Osiro, L.; Carpinetti, L. C. R. 2014. A comparison between fuzzy AHP and fuzzy TOPSIS methods to supplier selection, Applied Soft Computing 21: 194-209. https://doi.org/10.1016/j.asoc.2014.03.014

Kahraman, C.; Cebeci, U.; Ulukan, Z. 2003. Multi-criteria supplier selection using fuzzy AHP, Logistics Information Management 16(6): 382-394. https://doi.org/10.1108/09576050310503367

Kahraman, C.; Cebi, S.; Tuysuz, F. 2010. Fuzzy location selection techniques, Chapter 14 in C. Kahraman, M. Yavuz (Eds.). Production engineering and management under fuzziness. Berlin: Springer-Verlag Berlin Heidelberg. https://doi.org/10.1007/978-3-642-12052-7 14

Kannan, D.; Govindan, K.; Rajendran, S. 2015. Fuzzy Axiomatic Design approach based green supplier selection: A case study from Singapore, Journal of Cleaner Production 96: 194-208. https://doi.org/10.1016/j.jclepro.2013.12.076

Kannan, V. R.; Tan, K. C. 2002. Supplier selection and assessment: Their impact on business performance, Journal of Supply Chain Management 38(3): 11-21. https://doi.org/10.1111/j.1745-493X.2002.tb00139.x

Kaya, İ.; Kahraman, C. 2014. A comparison of fuzzy multicriteria decision making methods for intelligent building assessment, Journal of Civil Engineering and Management 20(1): 59-69. https://doi.org/10.3846/13923730.2013.801906

Kim, S.; Kim, Y. 2014. Computerized integrated project management system for a material pull strategy, Journal of Civil Engineering and Management 20(6): 849-863. https://doi.org/10.3846/13923730.2013.802743

Koskela, L. 1992. Application of the new production philosophy to construction. Technical Report No. 72, CIFE, Stanford University, Stanford, CA.

Li, W.; Cui, W.; Chen, Y.; Fu, Y. 2008. A group decision-making model for multi-criteria supplier selection in the presence of ordinal data, in IEEE International Conference on Service Operations and Logistics, and Informatics IEEE/ SOLI'2008, 12-15 October 2008, Beijing, China. https://doi.org/10.1109/SOLI.2008.4682799

Liu, J.; Ding, F. Y.; Lall, V. 2000. Using Data Envelopment Analysis to compare suppliers for supplier selection and performance improvement, Supply Chain Management: An International Journal 5(3): 143-150.

Mardani, A.; Jusoh, A.; M. D. Nor, K.; Khalifah, Z.; Zakwan, N.; Valipour, A. 2015. Multiple criteria decisionmaking techniques and their applications - a review of the literature from 2000 to 2014, Economic ResearchEkonomska Istraživanja 28(1): 516-571. https://doi.org/10.1080/1331677X.2015.1075139

Mendoza, A.; Ventura, J. A. 2013. Modeling actual transportation costs in supplier selection and order quantity allocation decisions, Operational Research 13(1): 5-25. https://doi.org/10.1007/s12351-011-0109-3

Meng, X. 2013. Change in UK construction: moving toward supply chain collaboration, Journal of Civil Engineering and Management 19(3): 422-432.

https://doi.org/10.3846/13923730.2012.760479

Monczka, R. M.; Handfield, R. B.; Giunipero, L. C.; Patterson, J. L. 2011. Purchasing and supply chain management. $5^{\text {th }}$ ed. Mason: Cengage Learning.

Muya, M.; Price, A. D. F.; Thorpe, A. 1997. Construction materials supply logistics, in $13^{\text {th }}$ Annual ARCOM Conference, 15-17 September 1997, Cambridge, UK.

Önüt, S.; Kara, S. S.; Işik, E. 2009. Long term supplier selection using a combined fuzzy MCDM approach: A case study for a telecommunication company, Expert Systems with Applications 36(2): 3887-3895. https://doi.org/10.1016/j.eswa.2008.02.045

Plebankiewicz, E.; Kubek, D. 2016. Multicriteria selection of the building material supplier using AHP and Fuzzy AHP, Journal of Construction Engineering and Management 142(1), 04015057. https://doi.org/10.1061/(ASCE)CO.1943-7862.0001033

Polat, G.; Arditi, D. 2005. The JIT materials management in developing countries, Construction Management and Economics 23(9): 697-712. https://doi.org/10.1080/01446190500041388

Polat, G.; Eray, E. 2015. An integrated approach using AHP-ER to supplier selection in railway projects, Procedia Engineering 123: 415-422. https://doi.org/10.1016/j.proeng.2015.10.068

Ren, Y.; Skibniewski, M. J.; Jiang, S. 2012. Building information modeling integrated with electronic commerce material procurement and supplier performance management system, Journal of Civil Engineering and Management 18(5): 642-654. https://doi.org/10.3846/13923730.2012.719835

Rutkowski, L. 2008. Computational intelligence methods and techniques. Berlin: Springer-Verlag Berlin Heidelberg. https://doi.org/10.1007/978-3-540-76288-1

Saaty, T. L. 1980. The analytic hierarchy process. New York: McGraw-Hill.

Safa, M.; Shahi, A.; Haas, C. T.; Hipel, K. W. 2014. Supplier selection process in an integrated construction materials management model, Automation in Construction 48: 6473. https://doi.org/10.1016/j.autcon.2014.08.008

Samarasinghe, D. A. S.; Tookey, J. E.; Rotimi, J. O. B.; Thiruchelvam, S. 2012. Supplier selection in the construction material purchasing function, in $4^{\text {th }}$ Annual American Business Research Conference, 4-5 June 2012, New York, USA.

Samvedi, A.; Jain, V.; Chan, F. T. S. 2013. Quantifying risks in a supply chain through integration of fuzzy AHP and fuzzy TOPSIS, International Journal of Production Research 51(8): 2433-2442. https://doi.org/10.1080/00207543.2012.741330

Schramm, F.; Morais, D. C. 2012. Decision support model for selecting and evaluating suppliers in the construction industry, Pesquisa Operacional 32(3): 643-662. https://doi.org/10.1590/S0101-74382012005000020 
Sevkli, M. 2010. An application of the fuzzy ELECTRE method for supplier selection, International Journal of Production Research 48(12): 3393-3405. https://doi.org/10.1080/00207540902814355

Sun, C. 2010. A performance evaluation model by integrating fuzzy AHP and fuzzy TOPSIS methods, Expert Systems with Applications 37(12): 7745-7754. https://doi.org/10.1016/j.eswa.2010.04.066

Tam, M. C. Y.; Tummala, V. M. R. 2001. An application of the AHP in vendor selection of a telecommunication system, Omega 29: 171-182. https://doi.org/10.1016/S0305-0483(00)00039-6

Taylan, O.; Bafail, A. O.; Abdulaal, R. M. S.; Kabli, M. R. 2014. Construction projects selection and risk assessment by Fuzzy AHP and Fuzzy TOPSIS methodologies, Applied Soft Computing 17: 105-116. https://doi.org/10.1016/j.asoc.2014.01.003

Thomas, H. R.; Riley, D. R.; Messner, J. I. 2005. Fundamental principles of site material management, Journal of Construction Engineering and Management 131(7): 808-815. https://doi.org/10.1061/(ASCE)07339364(2005)131:7(808)

Van Laarhoven, P. J. M.; Pedrycz, W. 1983. A fuzzy extension of Saaty's priority theory, Fuzzy Sets and Systems 11(1-3): 229-241. https://doi.org/10.1016/S0165-0114(83)80082-7

Van Weele, A. J. 2005. Purchasing and supply chain management: analysis, strategy, planning and practice. London: Thomson Learning.

Verma, R.; Pullman, M. E. 1998. An analysis of the supplier selection process, Omega 26(6): 739-750. https://doi.org/10.1016/S0305-0483(98)00023-1

Vrijhoef, R.; Koskela, L. 2000. The four roles of supply chain management in construction, European Journal of Purchasing \& Supply Management 6(3): 169-178. https://doi.org/10.1016/S0969-7012(00)00013-7

Wang, Y. X. 2005. Application of fuzzy decision optimum model in selecting supplier, The Journal of Science Technology and Engineering 5: 1100-1103.

Wang, W. P.; Tang, M. C. 2015. A multi-criteria assessment for R\&D innovation with fuzzy computing with words, in H. A. L. Thi, T. P. Dinh, N. T. Nguyen (Eds.). Modelling, computation and optimization in information systems and management sciences. Switzerland: Springer International Publishing. https://doi.org/10.1007/978-3-319-18167-7_1
Weber, C. A.; Current, J. R.; Benton, W. C. 1991. Vendor selection criteria and methods, European Journal of Operational Research 50: 2-18. https://doi.org/10.1016/0377-2217(91)90033-R

Wong, B. L.; Lai, V. S. 2011. A survey of the application of fuzzy set theory in production and operations management: 1998-2009, International Journal of Production Economics 129(1): 157-168. https://doi.org/10.1016/j.ijpe.2010.09.013

Wong, E. T. T.; Norman, G. 1997. Economic evaluation of materials planning systems for construction, Construction Management and Economics 15: 39-47. https://doi.org/10.1080/014461997373097

Wu, D. D.; Zhang, Y.; Wu, D.; Olson, D. L. 2010. Fuzzy multi-objective programming for supplier selection and risk modeling: A possibility approach, European Journal of Operational Research 200(3): 774-787. https://doi.org/10.1016/j.ejor.2009.01.026

Yazdani-Chamzini, A. 2014. An integrated fuzzy multi criteria group decision making model for handling equipment selection, Journal of Civil Engineering and Management 20(5): 660-673. https://doi.org/10.3846/13923730.2013.802714

Yazdani, M.; Zolfani, S. H.; Zavadskas, E. K. 2016. New integration of MCDM methods and QFD in the selection of green suppliers, Journal of Business Economics and Management 17(6): 1097-1113. https://doi.org/10.3846/16111699.2016.1165282

Zadeh, L. A. 1965. Fuzzy sets, Information and Control 8: 338353. https://doi.org/10.1016/S0019-9958(65)90241-X

Zadeh, L. A. 1975. The concept of a linguistic variable and its application to approximate reasoning, Information Sciences 8: 199-249. https://doi.org/10.1016/0020-0255(75)90036-5

Zavadskas, E. K.; Turskis, Z.; Kildiene, S. 2014. State of art surveys of overviews on MCDM/MADM methods, Technological and Economic Development of Economy 20(1): 165-179. https://doi.org/10.3846/20294913.2014.892037

Zeydan, M.; Çolpan, C.; Çobanoğlu, C. 2011. A combined methodology for supplier selection and performance evaluation, Expert Systems with Applications 38(3): 2741-2751. https://doi.org/10.1016/j.eswa.2010.08.064

Zhang, D.; Zhang, J.; Lai, K.; Lu, Y. 2009. A novel approach to supplier selection based on vague sets group decision, Expert Systems with Applications 36(5): 9557-9563. https://doi.org/10.1016/j.eswa.2008.07.053

Gul POLAT. She is a Professor of Civil Engineering at Istanbul Technical University. She conducted her PhD studies at Istanbul Technical University and Illinois Institute of Technology in Chicago. Her main areas of research interest include decision support techniques, bidding strategies, resource management, marketing management, risk management, precast concrete systems, and most aspects of construction management. She has been involved with several research projects funded by The Scientific and Technological Research Council of Turkey (TUBITAK), Istanbul Technical University (ITU), Feyzi Akkaya Fund for Supporting Scientific Activities (FABED), and other construction industry agencies. Her research work over the years has resulted in 87 technical papers in refereed journals and proceedings. She has served over the years on several organizing committees of national and international conferences. Dr. Polat is currently serving on the editorial board of an international journal and routinely reviews papers for several scholarly publications.

Ekin ERAY. She is a Research Assistant at the Department of Civil Engineering at Istanbul Technical University. She is currently a $\mathrm{PhD}$ candidate in the Structural Engineering program. She has been involved with one research project funded by Istanbul Technical University (ITU). Her research work over the years has resulted in 6 technical papers in refereed journals and proceedings.

Befrin Neval BINGOL. She is a Research Assistant at the Department of Civil Engineering at Istanbul Technical University. She received her PhD degree in the Structural Engineering program. She has been involved with two research projects funded by The Scientific and Technological Research Council of Turkey (TUBITAK) and Istanbul Technical University (ITU). Her research work over the years has resulted in 28 technical papers in refereed journals and proceedings. 